\title{
Energy systems engineering - a guided tour
}

\author{
C. Doga Demirhan ${ }^{1,2}$, William W. Tso ${ }^{1,2}$, Gerald S. Ogumerem ${ }^{1,2}$ and Efstratios N. Pistikopoulos ${ }^{1,2^{*}}$
}

\begin{abstract}
As future energy systems aim to be more efficient, cost-effective, environmentally benign, and interconnected with each other, their design and operation become ever challenging tasks for decision-makers, engineers, and scientists. Sustainability of life on earth will be heavily affected by the improvements of these complex energy systems. Therefore, experts from various fields need to come together to find common solution strategies. However, since different technologies are usually developed separately by their own technical community, a generally accepted unified systematic approach to tackle integrated systems is lacking. With this article, we want to introduce and highlight the power of energy systems engineering as a generic framework to arrive at synergistic solutions to complex energy and environmental problems. Tools of energy systems engineering are numerous, and its application areas cover a wide range of energy systems. In this commentary, we present an overview of state-of-the-art methodologies of energy systems engineering, list its applications and describe few examples in detail, and finally introduce some possible new directions.
\end{abstract}

Keywords: Energy systems engineering, Optimization, Mathematical modeling, Optimal design and operation, Multiple criteria decision-making, Uncertainty in design and operation

\section{Motivation}

With the growth in world economy and population, the global energy demand is projected to rise from 570 exajoules in 2015 to 1000 exajoules by 2070 [1, 2]. As a result, the energy availability and usage will continue to be key challenges our society faces. Today's heavily fossil fuel-based energy supply chain has developed successfully over decades to produce reliable, available, and affordable energy to various industries and sectors. Unfortunately, this dependence on fossil resources results in the release of large amounts of greenhouse gas (GHG) emissions that affect the environment and accelerate climate change $[3,4]$. Meeting the increasing energy demand, while reducing GHG emissions, will arguably be one of the biggest challenges for $21^{\text {st }}$ century engineers, scientists, economists, and policy makers.

Energy production, conversion, and delivery systems of the future should not only help us meet the increasing

\footnotetext{
*Correspondence: stratos@tamu.edu

${ }^{1}$ Artie McFerrin Department of Chemical Engineering, Texas A\&M University, College Station 77843, TX, USA

${ }^{2}$ Texas A\&M Energy Institute, Texas A\&M University, College Station 77843, TX, USA
}

energy demand and be economically feasible, but also (i) reduce GHG emissions and environmental pollution, (ii) increase energy savings while using less resources, and (iii) shift from fossil fuel-based technologies to larger shares of renewable resources [5-7]. These concerns prevail in various energy sectors such as power \& electricity generation, transportation, heavy industry, and residential \& commercial [8]. Additionally, operation of one sector affects the others since all these energy systems are to some degree connected [9]. In the past, each of these energy systems have been treated separately by their own technical community or political groups; however, holistic solution strategies are becoming more popular recently due to the possibility of exploiting the similarities, interconnections, and synergies between different energy systems [10].

As the integrated systems grow in complexity, a traditional method for energy systems design such as using heuristics that rely on rules of thumb become less useful to a decision-maker. While heuristics combined with experience can generate quick solutions that are often reasonably good, it does not provide a way to establish the quality of the solution. Furthermore, conflicting objectives or comparison of alternatives in a problem 
might require arbitrary decisions. As an alternative, highefficiency targeting approaches that focus on reaching thermodynamic limits can reduce energy consumption, but most of the time ignore capital cost considerations. They might also require considerable insight and trial \& error [11, 12]. In contrast to these two approaches, mathematical optimization-based methods that rely on algorithms and simultaneous consideration of physics, chemistry, biology, and economics in a system have proven themselves as promising tools to help decisionmakers generate design and operational strategies for integrated systems. Previously mentioned approaches can find good and near optimal solutions to a difficult problem. On the other hand, an optimization approach aims to find the best possible solution to the problem by quantifying the "goodness" of solutions. Optimization methods thrive when tackling systems with high degrees of freedom. Since integration means an increase in the degrees of the freedom, this translates into bigger room for improvement for energy systems. Rigorous optimization methods do not rely on trial \& error; instead, they are build on systematic solution strategies $[13,14]$

Energy systems engineering [15] methods aim to provide a generic framework to arrive at realistic integrated solutions to complex energy and environmental problems. Energy systems engineering puts mathematical optimization at its core to make systematic and quantitative analysis of design and operational decisions for energy systems ranging from nanoscale to megascale levels over time horizons that range from milliseconds to months or years $[10,16]$. Energy systems engineering has been successfully applied to optimizing design and operation in various sectors such as fuels and chemicals production and distribution [17-22], conventional and unconventional oil production [23-26], biofuels and biorefineries [27-29], and urban energy systems [30-33].

In this commentary, we aim to introduce some key methodologies of energy systems engineering to show the versatility and resourcefulness of its tools. Then, we present some representative case studies highlighting the application of these methodologies into energy systems of different scales. Finally, we will briefly comment on a few directions that will be explored more rigorously in the upcoming years.

\section{Methodologies of energy systems engineering}

The primary aims of energy systems engineering are the design and operation of energy intensive processes in a more efficient and economic manner through mathematical optimization. In this section, we present some of the important tools used in energy systems engineering. Figure 1 summarizes the concepts discussed below.

\section{Mathematical modeling}

Before we discuss the design and operation of energy systems, we first briefly mention how the equations describing energy systems (i.e. the constraints for optimization problems) are developed. Approaches for modeling energy systems [34] are: (1) first-principles, (2) datadriven, and (3) hybrid. First-principles modeling, also referred to as white-box, is using theory and mechanistic insights to derive the mathematical equations like mass, momentum, and energy balances that govern the energy system [35, 36]. A complete physical understanding of the energy system is presumed. On the other hand, data-driven or black-box models assume no physical insights and construct mathematical relationships solely based upon historical data from the energy system. Data-driven modeling is effective when a mechanistic understanding of the energy system is either not achievable or computationally too expensive. These datainspired surrogate models include regression, classification, interpolation, or artificial neural network techniques [37-39].

Incorporating concepts from both methods, hybrid or grey-box modeling is using theory and data to build a mathematical representation of the energy system. Some physical understanding is presumed; data is utilized to guide and adjust the first-principles equations in areas where there is a lack of insight [40-42]. Hybrid models are increasingly becoming a mainstay in energy systems engineering as energy systems grow more complex and pure theoretical approaches are not sufficient [43, 44], especially in applications such as renewable energy infrastructural design [45] and refinery manufacturing operations [46].

\section{Optimal design}

In the process systems engineering (PSE) community [47], design of energy systems is traditionally performed through a superstructure-based approach [48]. A superstructure is a systematic abstraction that consists of all possible alternatives in an energy system design including different system configurations, process integration, pathway interactions, operating conditions, and other important design parameters. For example, in designing a process for manufacturing a chemical product, possible alternatives could be different feedstocks, heat and power generation sources, technological units, and operational modes. This is the classical process synthesis problem $[49,50]$ that originates from optimizing the design of heat exchanger networks in the 1980s [51]. Other energy system design problems include molecular design [52-54], material discovery [55-57], process intensification [58-60], and supply chain networks [61-63]. From representing an energy system design as a superstructure through mathematical equations, an optimization 


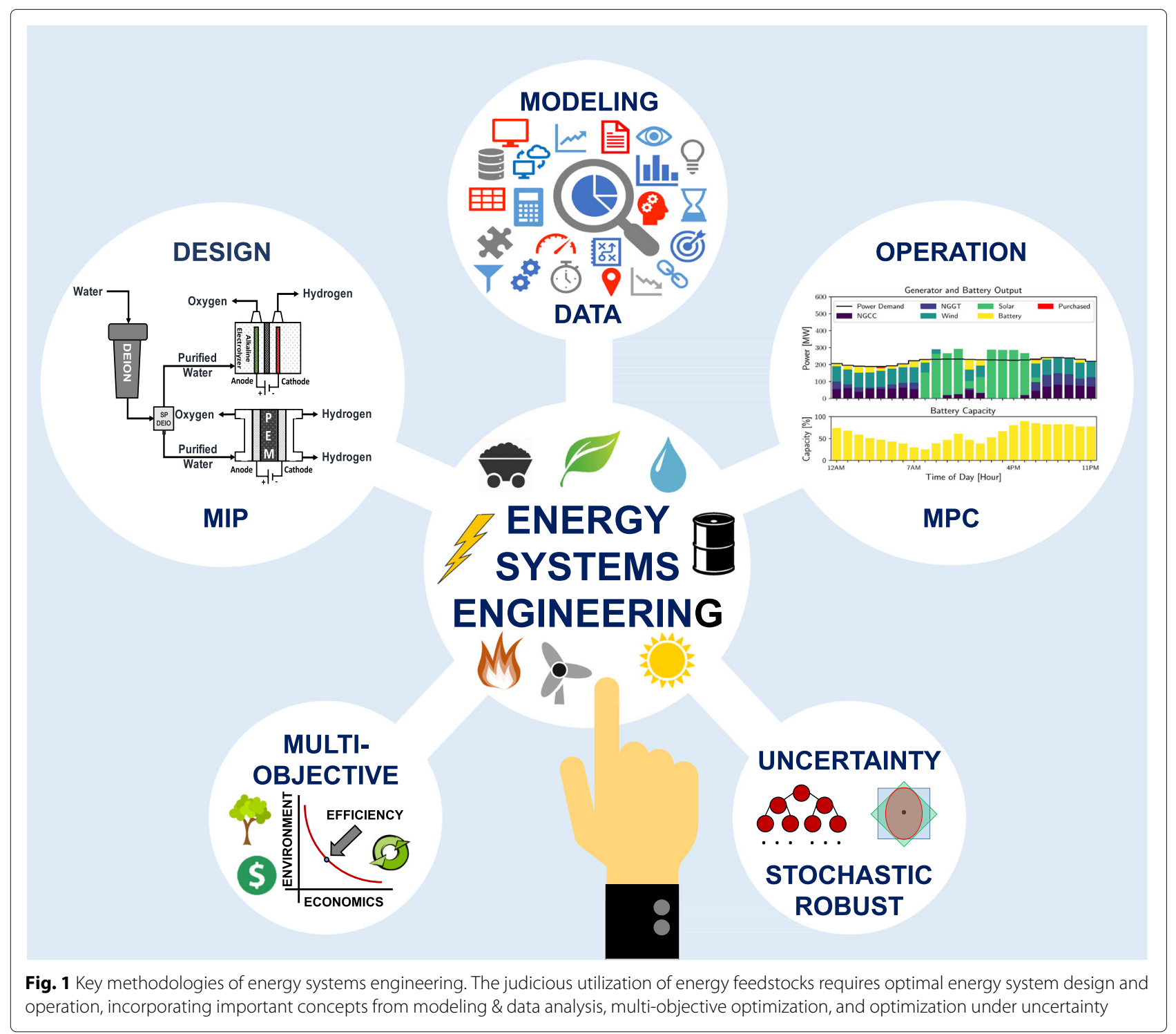

problem is formulated and solved to determine the optimal design from all other candidates.

Selection between design options is a discrete decision, while continuous modeling is needed to capture first principles like mass and energy balances. Linear programming (LP), first introduced in the 1930s and 40s $[64,65]$ to optimize military efforts during the war, handles continuous variables, but cannot illustrate discrete decision-making. By introducing binary (0-1) variables into the LP formulation, mixed-integer programming (MIP) is well-suited to model energy system superstructures [11]. In a MIP model, binary variables capture the discrete decisions and their realizations correspond to the selection (or not) of an alternative option. In fact, any logical condition between discrete events in a superstructure can be expressed through binary variables [66]. Depending on the nature of energy system, the continuous variables could be linearly or nonlinearly related, resulting in mixed-integer linear (MILP) or mixed-integer nonlinear (MINLP) problems. While solving MIP models has been a challenge, commercial solvers have dramatically improved over the years, especially for MILP problems, due to the significant developments in solution algorithms and increases in computational power $[67,68]$. Largescale MILP problems and modestly-sized MINLP problems are now routinely solved using commercial software. Nevertheless, customized algorithms are still necessary to solve specific instances of MIP problems, especially large-scale nonconvex MINLP types to global optimality [69-71].

\section{Optimal operation}

Once an energy system design has been implemented, the focus switches to its operation. Unlike the design 
phase, determining the optimal operation of an energy system involves temporal and dynamic considerations. An energy system is usually designed to operate at defined setpoints, and given certain conditions that actualize, it may operate at other setpoints as well. Control strategies are required to keep the energy system at these setpoints. For example, in keeping a reactor at a specific temperature or its product output at a targeted purity, proportional-integral-derivative (PID) controllers [72] are typically implemented. While these controllers are proven solutions, they do not provide any guarantee of optimality or stability because they are empirical and not model-based. In the PSE community, model predictive control (MPC) is a model-based control algorithm, first conceived in the 1979 by Cutler and Ramaker at Shell [73], for optimal and stable operation. State-space models derived from the energy system design are used for the MPC [74]. Analogies between control and other energy system operational issues at different timescales, such as production planning and scheduling [75-79], have been mentioned.

A complete rigorous modeling of energy system operations would necessitate dynamic programming (DP), where equations for each time period are fed as inputs into the equations for the next time period and so on in a recursive fashion. DP traces its development back to Bellman in the 1950s [80]. While a thorough approach, DP models are typically too large and complex to solve in a timely manner. They suffer from the curse of dimensionality as the amount of equations explodes exponentially as the number of time periods grows. As a workaround, instead of capturing the entire timeline, operational models for planning, scheduling, and control are usually applied in a discrete-time rolling or moving horizon manner [74]. Here, only a smaller horizon of the entire timeline is modeled initially, and then as time passes, the model is stepped forward in time by advancing this horizon. Operational models can be either linear or nonlinear; however, they are typically linear [81] as the time component already places a heavy computational burden on the solution of DP models and finding a feasible operation is sometimes more important than locating the absolute best, especially in scheduling problems [82]. Large-scale linear DP models are now regularly solved for energy system operations [83-86].

\section{Simultaneous design and operation}

Up until now, the design and operation of an energy system has been constructed as two separate problems; in actuality, they are intricately related and solution to one depends on the solution to the other. When considered alone, it is possible that an optimal design may not have a feasible operation, or vice versa. Moreover, separate optimal design and optimal operation may not reflect the true optimum of the overall energy system and lead to suboptimal results. Therefore, it is paramount to develop strategies to integrate together energy system design and operation $[87,88]$. One such method is multi-parametric programming $(\mathrm{mpP})$, where an optimization problem is solved for a range and as a function of multiple parameters [89]. mpP dates back to the 1950s, and early work originated in the field of sensitivity analysis for LP [90].

In a mpP model combining energy system design and operation, the operation can be optimized in terms of the design parameters - that is the optimal operation is expressed as a function of the design (i.e. a designdependent operation). In other words, mpP maps lower level decisions such as design to upper level decisions like control and scheduling [91]. An mpP approach has been utilized to investigate the simultaneous design and operation of a continuously stirred tank reactor, a binary distillation column, and a combined heat and power generation unit through design-dependent controllers [92]. Furthermore, as renewable energies consumption grows, the integration of design and operation will become an even more important research area within energy systems engineering for addressing intermittency [93-96].

\section{Multiple criteria decision making}

In constructing and solving these optimization problems, model equations describing the energy system become constraints, and the criterion one wishes to optimize over is the objective function. Typical criteria for energy systems are energy efficiency, economic performance, carbon footprint, and environmental impact indicators. Depending on the choice of objective function, the optimal solution will vary - there are competing interests among the different criteria. For example, in designing a gas combustion engine, an economic profit maximization may determine coal feedstock to be most lucrative, but an environmental emissions minimization may choose biomass as the eco-friendliest. While a single objective function, usually an economic one, is characteristic of most energy systems engineering problems, challenges with resource supplies and greenhouse gas emissions require energy systems that are holistically designed and operated with respect to efficiency, economics, and environmental factors [97-99]. Multi-objective optimization (MO), the simultaneous optimization according to two or more conflicting criteria, is one suitable strategy to consider the existing trade-offs among different objective functions [100-102]. The goal of MO is to calculate a Pareto front, a set of equally good optimal solutions, that captures these trade-offs between conflicting criteria [103]. A decision-maker can then make an optimal decision based upon his individual interests and preferences for different target levels for each criterion. The epsilon-constraint 
method is the most popular method for solving MO problems [104].

\section{Uncertainty in design and operation}

In all the optimization problems discussed thus far, parameter values have been assumed to be definitively known. In reality, this is often not the case, and there is some uncertainty associated with the parameters. For example, crude oil prices can fluctuate geographically and throughout the year; this influences the optimal design and operation of a refinery. Depending on what parameter values are realized, a solution to an optimization problem may no longer be optimal or even feasible because the parameter in a constraint has taken on a different value than what was first assumed when solving the problem. Actual realizations of uncertain parameters can affect the solution's quality. Therefore, it is important to account for sources of uncertainty in energy systems during the model development phase, especially since the uncertainty could propagate between different levels of the design or operation.

From a modeling prospective, uncertainty can be addressed either stochastically or probabilistically [105-107]. Stochastic programming (SP) treats the uncertain parameters as random variables that when considered together generate different scenarios over which to model and optimize [108, 109]. SP problems are typically solved using Monte Carlo [110] or stage-wise decomposition techniques like Bender's [111]. Robust optimization (RO) bounds uncertain parameters within uncertainty sets consisting of all possible realizations and assigns probabilities to parameter violation of bound [112-114]. While this guarantees feasibility, resulting robust solutions are often overly conservative. For this reason, probabilistic guarantees on constraint violation are implemented to improve the performance of robust solutions [115-120]. RO problems can be solved with commercial MIP solvers, after reformulating them as deterministic optimization problems using strong duality properties of LP. Notwithstanding, there is no agreed upon standard method to account for uncertainty. In the literature, both SP and RO have been employed to study energy systems of industrial importance $[121,122]$. The right technique likely depends on the specific energy system being studied [123].

These methodologies presented above form the fundamental basis of energy systems engineering. While not exhaustively comprehensive, the goal was to describe with sufficient detail the essence of energy systems engineering toward addressing the complex design and operation of energy systems. In the following sections, applications in several interesting energy systems are presented to highlight the utility and power of energy systems engineering.

\section{Applications of energy systems engineering}

The methodologies listed in the previous section have been applied to various energy systems. Interested readers are encouraged to read the following publications from our research group on the listed topics below:

1) Optimal production of fuels and chemicals through process synthesis [124-127]

2) Supply chain analysis of fuels and chemicals $[128$, 129]

3) Polygeneration energy systems [130-132]

4) Combined heat and power generation systems [92, 133, 134]

5) Design and operation of fuel cells and electrolyzers [135-138]

6) Food-energy-water nexus [139-141]

7) Fault detection and diagnosis in chemical processes $[142,143]$

To show the power of energy systems engineering analyses, we will present a few studies in detail in this chapter. Selected are three examples of an energy systems engineering approach to tackle the multi-faceted and multiscale challenges in the design, supply chain, and operation of producing energy carriers. We will first present our optimal energy carrier production process design using process synthesis, then follow with a supply chain analysis of Texas. After that, we will show how design and operation of a PEM electrolyzer can be considered simultaneously using $\mathrm{mpP}$ techniques.

\section{Process synthesis and global optimization for sustainable ammonia production}

Ammonia is one of the most widely produced chemicals in the world. Global ammonia production in 2015 was reported to be over 140 million tons [144]. While currently more than $80 \%$ of the produced ammonia is used for fertilizer production, it also offers a promising potential as a renewable energy carrier. If produced from renewable resources, ammonia does not produce any GHGs when converted back to power. It has a high hydrogen content (17.8 wt.\%) and more favorable storage and transportation characteristics compared to other energy carriers like pressurized or liquefied hydrogen [145]. Due to this dual opportunity, demand for ammonia in the future is expected to grow. While industrial ammonia synthesis (Eq. 1) by the famous Haber-Bosch process is very-well established and has been finely optimized during its 100 years of practice, it is energy intensive (requires 28-30 $\mathrm{GJ} /$ ton of ammonia) and has a significant carbon footprint (on average 2.8 tons of $\mathrm{CO}_{2}$ /ton of ammonia) due to its dependence on fossil feedstocks for hydrogen and power generation [146, 147].

$$
\mathrm{N}_{2}+3 \mathrm{H}_{2} \rightleftharpoons 2 \mathrm{NH}_{3}, \quad \Delta H^{\circ}=-91.4 \mathrm{~kJ} / \mathrm{mol}
$$


In their work, Demirhan et al. [127] used process synthesis and superstructure optimization to compare ammonia production from different renewable feedstocks and production routes. They analyzed the economic feasibility of sustainable ammonia production through comparing the effects of GHG emission restrictions, plant location (i.e. different utility and feedstock prices and availability), and plant scales on production costs. The natural gas-based production route is used as a reference case.

A conceptual design of the ammonia production facility is illustrated in Fig. 2. It consists of three main components: (i) plant, (ii) utility system, and (iii) heat recovery system. These components are highly integrated; they exchange power, heat, and process streams. The plant takes in raw materials and converts them to products. Depending on the process, the plant can consume or generate electricity and/or heat. The ammonia plant has subsections in itself: (1) natural gas reforming, (2) biomass gasification, (3) water electrolysis, (4) synthesis gas cleaning, (5) air separation unit, and (6) Haber-Bosch process for ammonia synthesis. Each of these subsections can involve reactor, separation, and recycle subsystems. Process alternatives of the plant and the connections are presented in Fig. 3. The utility system consists of heat and power generation units and waste water treatment facilities. It takes fuel, air, and water to provide the ammonia plant with electricity, power, and steam. It also provides the heat recovery system with hot and cold utilities. Heat recovery system plays a very important role in utilizing the wasted heat from the ammonia plant to minimize the hot and cold utility requirements. Process synthesis strategies can generate optimal process flowsheets with simultaneous heat, power, and water integration by exploiting the interactions between these three components [148, 149].

When all the technology alternatives, operating condition options, interconnections, and heat, power, and water integration systems are embedded in the postulated process superstructure, a large scale nonconvex MINLP is obtained in the form shown in Eq. 2,

$$
\begin{array}{ll}
\min _{x, y} & f(x, y) \\
\text { s.t. } & h(x, y)=0 \\
& g(x, y) \leq 0 \\
& x \in R^{n} \\
& y \in\{0,1\}^{k}
\end{array}
$$

where $x$ is a vector of continuous variables that represents the molar flow rates, compositions of the process streams, split fractions, total enthalpy flows, transferred or absorbed heat, and costs of the processing units.

$y$ is a vector of $0-1$ variables that denote the potential existence of a process unit (e.g. 1 if a unit is selected, 0 else).

$f(x, y)$, the objective function, is the performance criterion that is the levelized total cost of ammonia production.

$h(x, y)$ are the equality constraints that denote stream connections, total mass/component/atomic balances, energy balances, equilibrium relationships, input-output relationships for black-box units which constitute the process constraints as well as unit investment costs functions. $g(x, y)$ are the inequality constraints which correspond to design specifications, restrictions (e.g. GHG emissions,

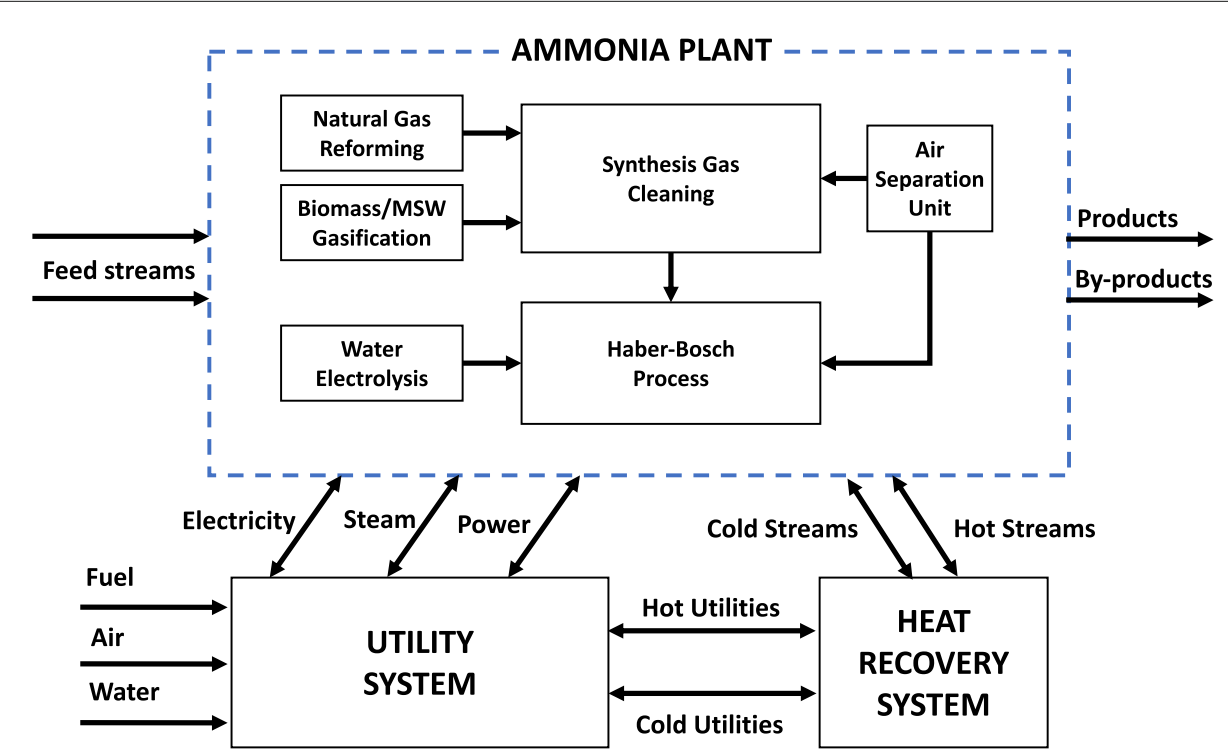

Fig. 2 Conceptual design of a process. Overall process consists of three main components: plant, utility system, and heat recovery system 


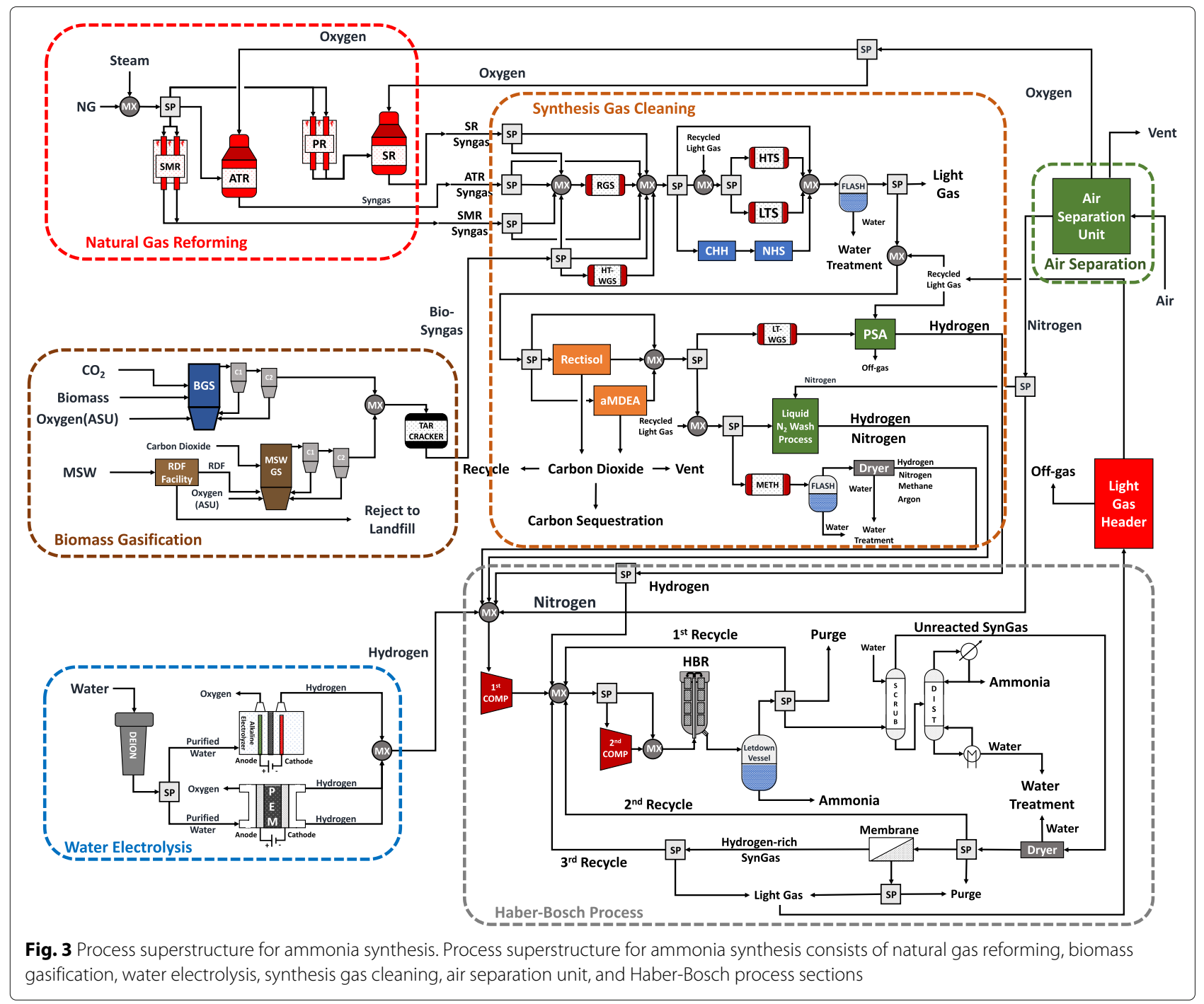

product purities, etc.), feasibility constraints, and logical constraints (e.g. select only one type of reactor). Solution of such large nonconvex MINLPs requires global optimization techniques and tailored algorithms. Interested readers are encourage to read work by Floudas and coworkers to learn more about the global optimization methods used in this work [70, 148].

One case study from the work focused on ammonia production in Texas (TX), where GHG emissions are restricted to $25 \%$ of a traditional natural gas-based ammonia plant and production capacity is set as 500 metric tons/day. Considered production routes include natural gas reforming (NG), hardwood-type (HW) forest residue gasification, municipal solid waste (MSW) type biomass gasification, wind-powered water electrolysis (W), and solar-powered water-electrolysis (S). Tables 1 and 2 show the total production cost and investment cost breakdowns.
Table 1 Total production cost breakdown of ammonia plants for Texas

\begin{tabular}{llllll}
\hline $\begin{array}{l}\text { Cost } \\
\text { contributions }\end{array}$ & \multicolumn{7}{l}{ TX-NG-500 TX-HW-500 TX-MSW-500 TX-W-500 TX-S-500 } \\
\hline Biomass & 0.00 & 120.21 & 107.44 & 0.00 & 0.00 \\
Natural gas & 85.34 & 0.00 & 0.00 & 0.00 & 0.00 \\
Water & 0.69 & 0.99 & 0.99 & 2.41 & 2.38 \\
Investment & 229.52 & 211.77 & 277.02 & 233.46 & 240.10 \\
CO $_{2}$ TS\&M & 7.26 & 0.07 & 0.00 & 0.00 & 0.00 \\
OM & 60.60 & 55.91 & 73.14 & 61.63 & 63.39 \\
Electricity & 88.66 & 45.53 & 56.75 & 532.43 & 610.49 \\
BEP (\$/ton & 472.05 & 434.48 & 515.36 & 829.93 & 916.33 \\
Ammonia) & & & & & \\
\hline
\end{tabular}


Table 2 Investment cost breakdown of ammonia plants for Texas

\begin{tabular}{|c|c|c|c|c|c|}
\hline Plant section & TX-NG-500 & TX-HW-500 & TX-MSW-500 & TX-W-500 & TX-S-500 \\
\hline $\begin{array}{l}\text { Syngas } \\
\text { generation }\end{array}$ & 51.72 & 60.50 & 131.72 & 0.00 & 0.00 \\
\hline $\begin{array}{l}\text { Syngas } \\
\text { Cleanup }\end{array}$ & 49.71 & 28.65 & 31.95 & 0.31 & 0.31 \\
\hline $\begin{array}{l}\text { Ammonia } \\
\text { Syn. Loop }\end{array}$ & 67.98 & 61.64 & 61.64 & 61.64 & 61.64 \\
\hline $\begin{array}{l}\text { Water } \\
\text { Electrolysis }\end{array}$ & 0.00 & 0.00 & 0.00 & 121.75 & 121.75 \\
\hline Air Separation & 50.14 & 41.31 & 41.31 & 41.31 & 41.31 \\
\hline $\begin{array}{l}\text { H\&P } \\
\text { Integration }\end{array}$ & 15.31 & 20.76 & 16.06 & 0.00 & 7.40 \\
\hline $\begin{array}{l}\text { Wastewater } \\
\text { Treatment }\end{array}$ & 10.89 & 13.53 & 13.82 & 24.97 & 24.67 \\
\hline Total (MM\$) & 245.75 & 226.75 & 296.63 & 249.97 & 257.08 \\
\hline
\end{tabular}

TX-HW-500 production cost is lower than that of the base case TX-NG-500. TX-MSW-500 has higher production costs, mainly due to expensive cleaning operation used for MSW processing. Wind- or solar-powered water electrolysis-based ammonia production has high production costs, due to high electricity consumption of the electrolyzers. Sensitivity studies show that water electrolysisbased ammonia production only becomes competitive when renewable electricity prices are very low. This is important to note, because the excess electricity production from renewables can often be sold at a negative price in states like California to prevent overloading the grid. Such excess production can be used to power electrolysis to store intermittent solar resources in renewable ammonia.

\section{Energy carriers supply chain optimization}

A challenging barrier to greater integration of renewable energies such as solar and wind is their intermittency. Solar irradiation and wind speeds fluctuate hourly, daily, seasonally, and geographically. Moreover, solar and wind availabilities are often asynchronous with consumer energy demands. One potential solution to the intermittency problem is storing energy during periods and in areas of excess supply. Later on, the stored energy can be utilized when renewable energies are not directly available. The DOE [150], IRENA [151], and IEA [152] have acknowledged that developing cost-effective energy storages is a crucial step for the wider adoption of renewable energies. Options for electrical energy storage include pumped-storage hydroelectricity (PSH), compressed air energy storage (CAES), batteries, and chemical compounds $[153,154]$.

While they are mature and already deployed large-scale technologies, PSH and CAES are geographically limited in their suitable construction sites. On the other hand, the storage capacity of batteries is much smaller. At current costs, the scale-up of batteries is prohibitively expensive, and they are more fit for distributed applications $[152,155]$. Energy can be stored in chemical compounds through renewable energy powered water electrolysis to produce hydrogen [156]. Other chemicals, such as ammonia $[157,158]$ and methanol [159], can also be synthesized from hydrogen. Storing energy in chemicals is attractive because their production is well-studied, can be easily scaled up to large volumes, and benefits from economies of scale. Moreover, chemicals have higher energy content than batteries and are geographically flexible in terms of where they can be produced and consumed. In this latter regard, chemicals can act as energy carriers, storing and transporting renewable energy from regions of excess supply to demand areas (Fig. 4). Energy carriers are then converted back to electricity on-demand through fuel cells or gas turbines. Compared to other storage media, energy carriers have several more intermediary steps, and this is an existing cost barrier to overcome.

An infrastructure that coordinates the logistics of carriers storing and transporting energy is a complex energy system in which the optimal design is not self-evident. Among other decisions, it requires the following key considerations: which renewable resources to utilize as feedstock, which energy carriers to produce, what types of production facilities to build, where to build, what means to transport carriers, where to send them, and what conversion technologies to use. Methodologies from energy system engineering are needed to design a costeffective energy carrier supply chain network that maximizes the carriers' potential and is competitive with PSH, CAES, and batteries. Previous works [129, 160-162] have only consider single energy carriers in the supply chain, when in fact the optimal may include a combination of multiple ones. Here, all carrier options are collected into a network superstructure and modeled using a MILP formulation. Figure 5 shows the necessary input parameters into an energy carrier supply chain model. Binary variables determine the location and type of production facilities and conversion technologies, whereas continuous variables are associated with network flows and power capacities. Equality constraints denote network flow balances, while inequalities govern resource limitations and logical constraints. The overall objective function of the model (Eq. 3) is to minimize the levelized cost of electricity (LCOE) delivered at the demand locations.

$$
\begin{aligned}
\min & \text { Cost }_{\text {Invest }}+\text { Cost }_{\text {O\&M }}+\text { Cost }_{\text {Feedstock }}+\text { Cost }_{\text {Transport }} \\
& + \text { Cost }_{\text {Storage }}+\text { Cost }_{\text {Land }}-\text { Sales }_{\text {Oxygen }}
\end{aligned}
$$

A preliminary case study implementing the aforementioned MILP model is considered for designing an energy carrier supply chain network in Texas. Wind energy is 
concentrated in the central and northern part of the state, whereas solar energy is most abundant in the west; however, the majority of the population lives closer to the eastern part. In this setup, energy carriers are storing and transporting renewable energy from resource-rich areas to the five most populous cities in Texas. Using energy carriers to replace $100 \%$ of the electricity demand, assuming 3-month storage time, the LCOE is $\$ 0.556 / \mathrm{kWh}$ with the total energy carrier profile being $0.2 \%$ hydrogen, 55.5\% ammonia, and 44.3\% methanol (Fig. 6). About $91.7 \%$ of the renewable energy utilized for energy carrier production comes from wind, and the production facilities are expectedly built near concentrated wind resources. Mostly rail is used for long distance transport,
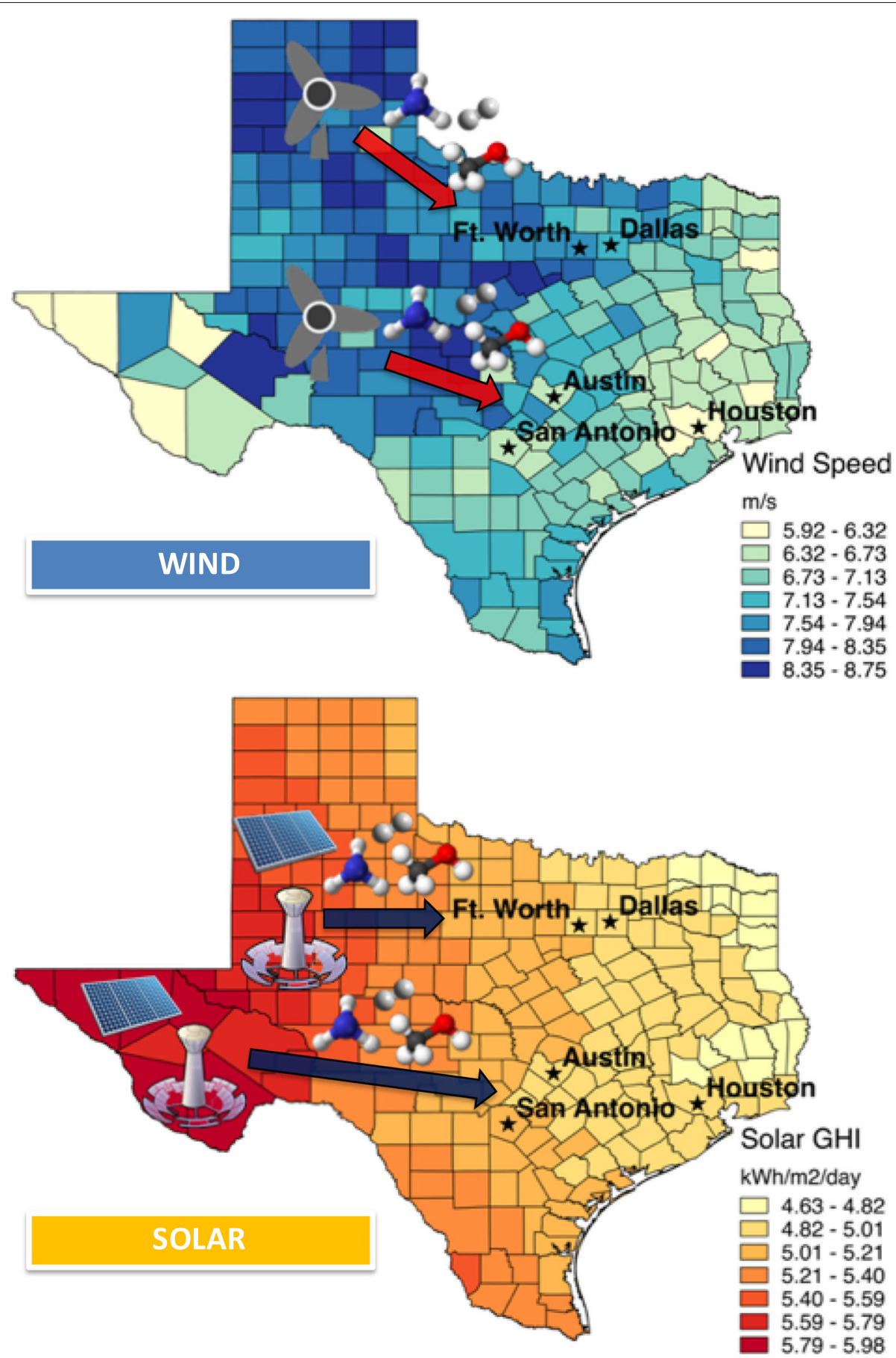

Fig. 4 Geographic mismatch of renewable energy and population in Texas. Solar and wind energy is concentrated away from the five most populous cities: Houston, Dallas, Ft. Worth, San Antonio, and Austin. Energy carriers can be used to bridge this mismatch 
while truck is deployed for shorter distance deliveries. This optimal, though conservative, LCOE is very competitive with projected numbers from PSH, CAES, and batteries. Other investigated scenarios will be part of a subsequent publication [163].

\section{Simultaneous design and control of PEM electrolyzers}

Water electrolysis for producing hydrogen is crucial to realizing sustainable ammonia production and energy carriers because it is the most upstream component in either energy system. Likewise, the electrolyzer alone is an important energy system. There are three major kinds of water electrolysis: alkaline, proton exchange membrane (PEM), and solid oxide [164]. The PEM water electrolysis process involves three major process units as shown in Fig. 7: oxygen and water management unit, electrolyzer stack, and hydrogen management unit. Water is first purified in the water management unit where ions are removed to prevent catalyst poisoning. Dissolved oxygen byproduct is also removed here. The water then goes into the electrolyzer stack where the reaction takes place. Produced hydrogen is finally separated from the unreacted water in the hydrogen management.

An advantage for PEM electrolyzers is their ability to operate at high current density, which increases the hydrogen production rate [165]. While this potentially reduces the operating cost of the electrolyzer, high current density also lowers the efficiency of the system due to increased energy losses due to faradaic resistance and overpotentials [165-167]. Therefore, there is an optimal current density to operate at. Another operational consideration for PEM electrolyzers is the inlet water flowrate. The water electrolysis reaction is theoretically endothermic, but because of these energy losses, heat is generated in the process due to Joule heating. Some of the reactant water is thereby used to cool and regulate the temperature across the electrolyzer stacks. Safe operation of PEM electrolyzers requires maintaining this temperature below a certain threshold. An increased water flowrate can also reduce the effects of overpotentials such as bubble coverage [168]. Consequently, there is an optimal operating point for inlet water flowrate as well.

Because of these different operational objectives, modeling approaches [169-171] from energy system engineering are needed to develop optimal operating strategies that integrate with the PEM electrolyzer design. For example, it is unnecessary to overdesign an electrolyzer stack (increasing its capital investment cost) to handle a maximum current density and water flowrate if these values will never be realized during the operation. First, highfidelity dynamic models of PEM electrolysis are developed to represent the electrochemistry and mass \& energy balances. This allows for an accurate simulation and digital twin of the PEM electrolyzer. Next, these models are reduced through statistical data methods (i.e. system identification of input/output data) to create approximate models to be used as input in the controller design. A multi-parametric model predictive control (mpMPC) approach is used to construct operating strategies that account for the electrolyzer design. The mpMPC [172] is a mpP-inspired exact reformulation of the classical linear quadratic regulator (LQR) problem (Eq. 4), allowing

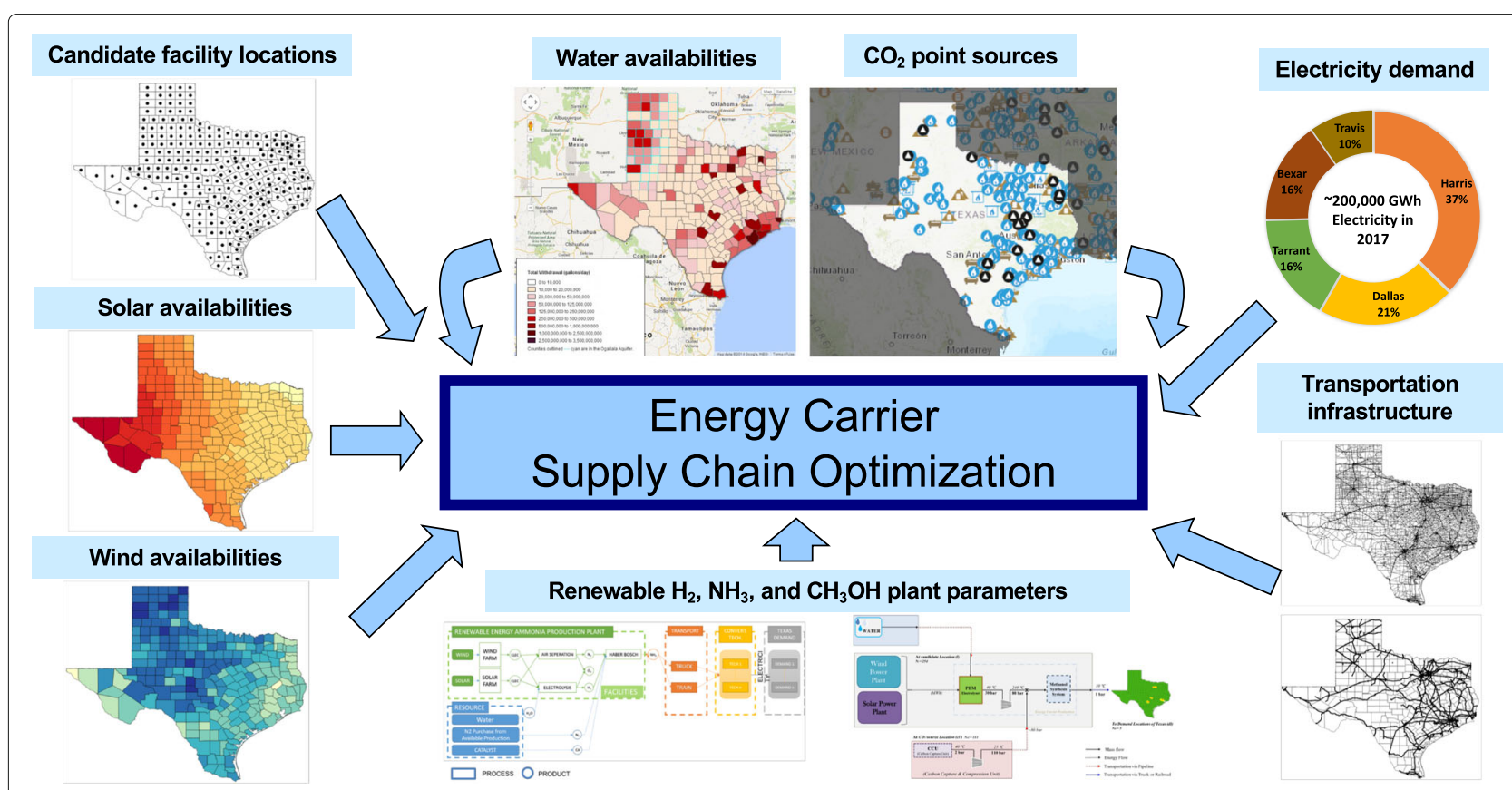

Fig. 5 Inputs for energy carrier supply chain. Important to accurately incorporate relevant parameters from databases into the model 


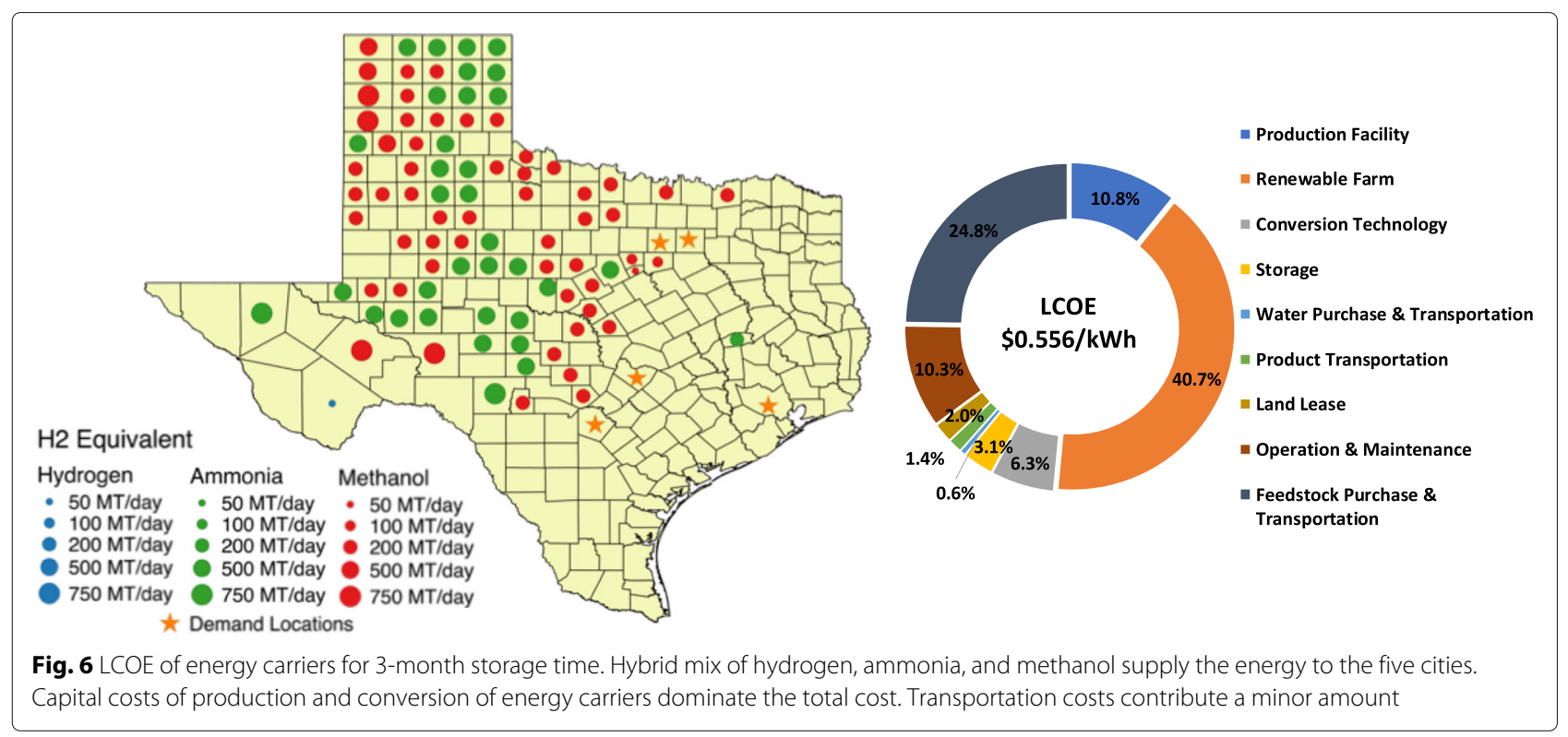

control laws to be explicitly expressed as a function of design parameters such as electrolyzer size and membrane material. The classical LQR for optimal operation is:

$$
\begin{aligned}
\min _{u} J & =\sum_{k=1}^{N-1}\left(y_{k}-y_{k}^{R}\right)^{T} Q R\left(y_{k}-y_{k}^{R}\right)+\sum_{k=0}^{M-1} \Delta u_{k}^{T} R \Delta u_{k} \\
\text { s.t. } & x_{k+1}=A x_{k}+B u_{k} \\
& y_{k}=C x_{k}+D u_{k}+e \\
& u_{\text {min }} \leq u_{k} \leq u_{\max } \\
& \Delta u_{\min } \leq \Delta u_{k} \leq \Delta u_{\max } \\
& x_{\min } \leq x_{k} \leq x_{\max } \\
& y_{\min } \leq y_{k} \leq y_{\max } \\
& u=\left[u_{0}, u_{1}, \ldots, u_{m-1}\right]
\end{aligned}
$$

where $x$ is the state variables; $u_{k}$ are the control variables; $\Delta u_{k}$ denotes the difference between two consecutive control actions; $y_{k}$ and $y_{k}^{R}$ are the outputs and their respective set points; $R$ and $Q R$ are the corresponding weights in the quadratic objective function; $N$ and $M$ are the output horizon and control horizon, respectively; $k$ is the time step; $A, B, C$, and $D$ are the matrices of the discrete linear state-space model; and e denotes the mismatch between the actual system output and the predicted output at initial time.

In this manner, the simultaneous optimization of energy system design and operation is performed. These collective steps comprise the Parametric Optimization and Control (PAROC) framework (Fig. 8), an integrated software platform that facilitates this simultaneous optimization [89].

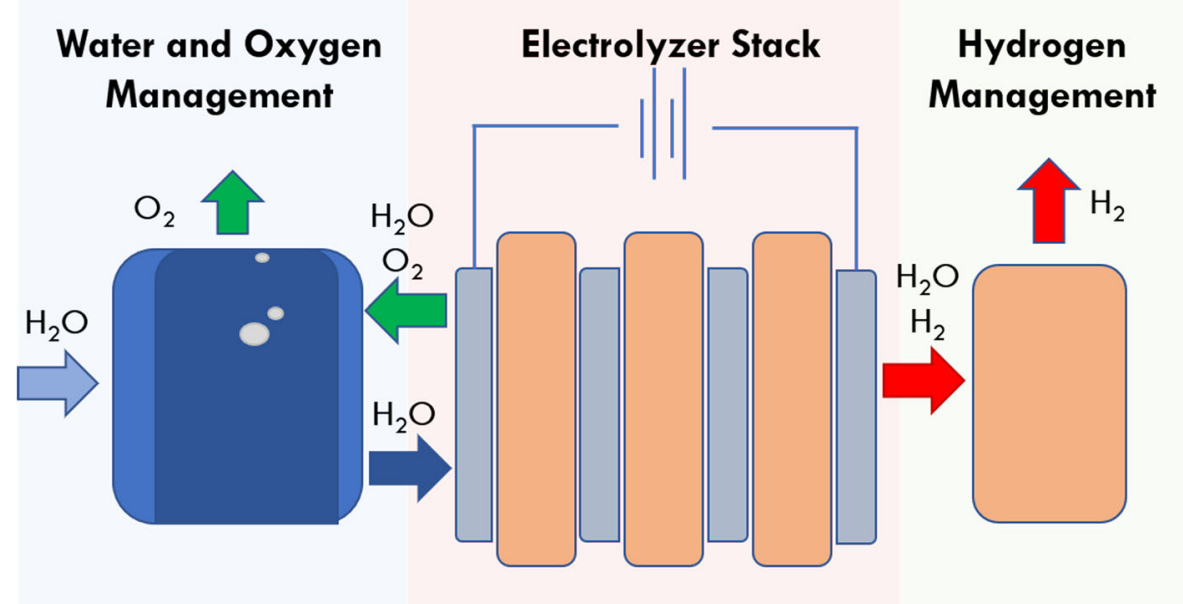

Fig. 7 PEM water electrolysis. An overview of the major parts comprising the system 
Ogumerem and Pistikopoluos [138] applied the PAROC framework toward optimizing the control strategy for a PEM electrolyzer. They observed that a mpMPC approach allowed them to optimally operate a PEM electrolyzer below cell voltage and temperature limits, while using inlet water flowrate as the manipulated variable. It is also confirmed that the water flowrate is better at responding to temperature changes, while current density is better for adjusting operation for changes in cell voltage. The mpMPC model elucidated explicit control laws depending on the state of the electrolyzer (Fig. 9) and setups subsequent work on simultaneous optimization for the design and operation of PEM electrolyzers. The mathematical equations expressing the control laws can be included as additional constraints in a superstructure MIP formulation for PEM electrolyzer design. Thereby, in this fashion, the design will be optimized with regards to the optimal operation determined from the MPC. This will minimize the capital and operating costs of PEM electrolyzers, making them more competitive with their alkaline counterparts.

\section{New directions}

In the previous sections, we described energy systems engineering methodologies and showed a couple of examples to highlight their usefulness in the analysis of an energy carrier system. As the energy sources and systems continue to evolve, so will the energy systems engineering methods and application areas. Exciting developments

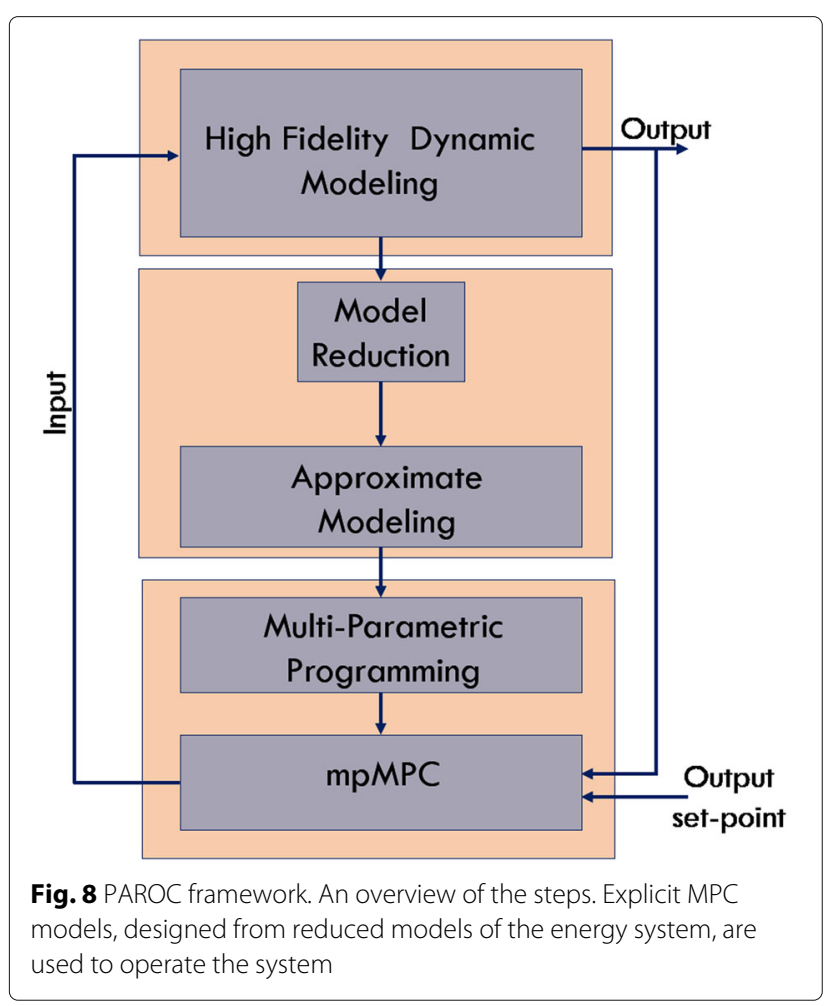

in various disciplines and fields have occurred in recent years and before concluding this article, we want to touch upon a few directions that we think will be explored more vigorously in the upcoming years by energy systems engineers.

\section{Information technologies in design and operation of energy systems}

Manufacturing facilities collect large amounts of operational data thanks to improved sensor and monitoring technologies. However, usefulness of data is limited without any strong data integration, classification, visualization, and analysis methods [173]. In their 2018 article, Edgar and Pistikopoulos [174] report that many U.S. manufacturing operations are data rich and knowledge poor. They indicate that while operations use sophisticated modeling and control technologies, usage of data analytics tools in the decision-making phase is still constrained. Integrating manufacturing intelligence in real-time across an entire production operation does not currently exist. The concept of smart manufacturing (SM) is defined as using the right data in the right form, the right technology and the right operations, wherever and whenever needed throughout the manufacturing enterprise. SM combines operations technology with information technology to improve the manufacturing platforms. Integrated modeling approaches that combine sensors and monitoring, data analytics, real-time data management and cloud technologies with control and automation will become more important in the future.

\section{Implications of artificial intelligence and machine learning for energy systems engineering}

While artificial intelligence and machine learning have been ongoing research areas for many decades [175-177], only recently have they gained wider attention due to the information age's explosion of data and increasing computational power [178]. Recent notable achievements with IBM's Watson and Google's AlphaGo have even garnered the interest of the greater public and brought promises of how "big data" can revolutionize the way we understand and study the world $[179,180]$. However, as with any new technological development, it might be better to remain cautiously optimistic to not overhype the fruits and oversell the perils, since there is still much progress to be made for artificial intelligence and machine learning to mature, penetrate, and spread to greater adoption. With enough time and directed efforts, we expect the advances in the artificial intelligence and machine learning community will migrate into energy systems engineering and become as commonly utilized methodologies as mixed-integer optimization and MPC have become in the last few decades [181]. Research fields such as catalyst design [182, 183] and drug discovery [184] are actively 


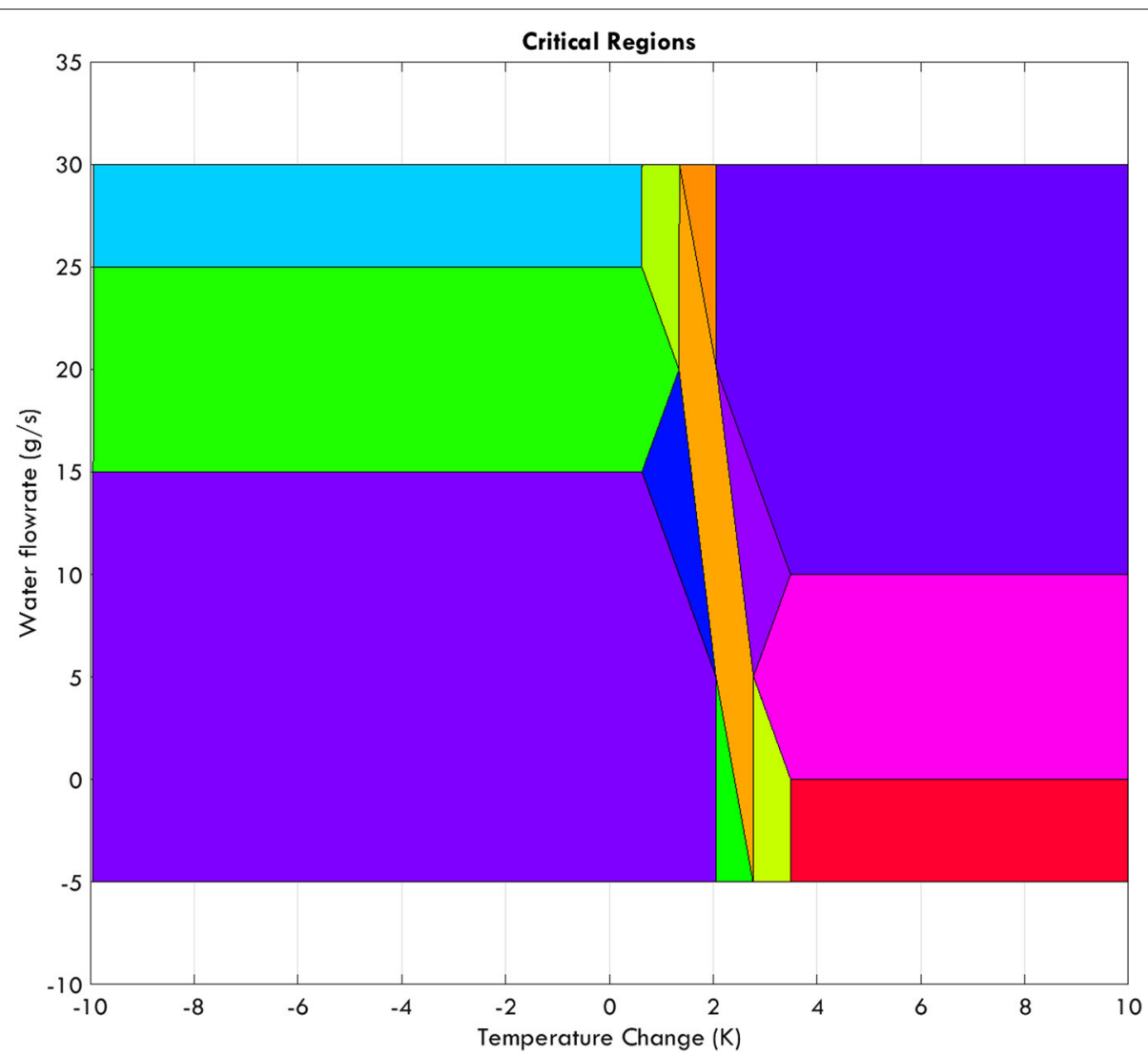

Fig. 9 Critical regions for simultaneous design and operation of PEM electrolyzer. Each region represents a separate optimal operating strategy for an unique set of design parameters for PEM electrolysis. MPMPC determines the design-dependent operation

developing open databases to simulate data-driven and hybrid model building. Artificial intelligence and machine learning will be especially needed in areas, such as process operation and fault diagnosis, where traditional mathematical approaches are not suitable due to a lack of a first-principles basis for model development.

There are now more ample resources and accessible software to learn and implement artificial intelligence and machine learning applications compared to earlier eras. The increasing number of such tools allow users to easily code their own machine learning or neural network models with little effort. In his engaging perspective on the status of artificial intelligence in chemical engineering, Venkatasubramanian [181] points out that there is a risk of substituting the well-trained usage of such tools for actual mastery of artificial intelligence and machine learning knowledge. We agree with his assessment that it is important for future engineers to be properly educated in the "know-why" rather than just the "know-how". We think there is a need to reform the current engineering curriculum and graduate training to include more artificial intelligence and machine learning material in order to better prepare individuals for advancing the energy systems of the future.

Extending the boundaries: Increased interdisciplinary work In this article, we presented applications focusing on mainly chemical engineering topics. Other disciplines such as electrical, mechanical, and civil engineering, physics, chemistry, biology, operations research, statistics, computer science, agriculture, economics, political science, and law also conduct extensive research on energy systems. Each of these disciplines has its own areas of focus, goals, solution strategies, and challenges related its problems. However, as the energy systems get more complex and interconnected, close cooperation of experts from such fields becomes a necessity. One such area that has manifested itself as an interdisciplinary field is the food, energy, and water nexus (FEW-N). In FEW-N, needs for each resource are linked to both global demands as well as their interdependency. This field brings researchers, stakeholders, and policy makers together to tackle problems that are too big to deal with by each of the individual community [185]. Recent 
work showed that energy systems engineering methods can be useful in modeling and exploiting the interconnections between these resources. By coming up with metrics to make sure that all perspective are equally considered, energy systems engineering methods can provide solutions that are feasible, sustainable, and effective $[139,186]$.

We expect new interdisciplinary fields to emerge in the following years. Academic and government initiatives play a key role here to advocate interdisciplinary work. Over the recent years, we have seen an increase in the activities of university institutes focusing on energy research across the USA. Such institutes try to bring experts from the aforementioned fields together on joint projects, so that the capabilities of each discipline are understood and synergies between collaborations can be exploited. A further indicator of academia's emphasis on interdisciplinary work is the rise in the number of master of science and master of engineering programs on energy systems in the USA. These programs have curriculum that cover topics from various engineering disciplines and social sciences to cultivate a generation of decision-makers with holistic and broader views of the energy landscape. It is our opinion, that energy systems engineering courses can play a pivotal role in bringing different disciplines together.

\section{Extending the scope: Increased industry-academia collaboration}

Another field that we expect to grow in the future is the industry-academia collaborations. So far, aims of the optimization community and industry have been different. The value of novel optimization-based energy systems engineering tools have been somewhat underestimated by industry, and therefore, unevenly utilized [187]. Academia products are high impact and peer-reviewed open publications so that funding can be ensured. The peer-review process favors fast publications with novel \& sophisticated methodologies. For this reason, academia products, especially in energy systems engineering, are in the form of prototypical software. On the other hand, industry is interested in basic ideas and their resulting benefits. Industry does not show interest in migrating information between multiple tools and software packages. Additionally, most companies limit their information exchange with academia due to confidentiality reasons. As a result, academia has limited access to realistic cases [7]. However, this picture is likely to change in the future. As Department of Energy supported initiatives like Rapid Advancement in Process Intensification (RAPID) Manufacturing Institute and Clean Energy Smart Manufacturing Innovation Institute (CESMII) show, collaborations between industry and academia can work effectively when the research objectives are clearly presented for both parties [188, 189].

\section{New modeling environments and strategies for optimal design and operation}

Two of the most widely established modeling environments used for the formulation and optimization of algebraic problems are GAMS [190] and AMPL [191]. These are commercial high-level programming platforms where modeling is done by explicitly declaring all the variables, constraints, and parameters in an optimization program. While these environments have access to numerous solvers and have been used extensively by the optimization community, they suffer from difficulties in data input, manipulation, visualization, and implementation of advanced algorithms. Introduction of recent modeling environments, such as PyOMO [192] and JuMP [193] that are built upon Python and Julia programming languages, respectively, present an alternative approach via use of object-oriented programming (OOP). Both environments allow users direct access to modeling objects that are given in a model library. By doing that, the users do not have to specify governing equations, every time they add a unit to a process. This will hopefully help modelers make designs in a more standardized, intuitive way, and an easier way. PyOMO and JuMP currently have limited access to optimization solvers. However, they are license-free and open-source environments. Another difficulty with the traditional way of formulating optimization problems is modeling of process alternatives using integer variables. There is no unique way to express the logic encapsulated in the superstructure as a set of variables and constraints. Generalized disjunctive programming (GDP) techniques offer new alternatives to traditional mixed-integer modeling approaches, by directly addressing the relationships between two distinct alternatives (disjunctions) via logicbased methods $[194,195]$. OOP can work well with GDP techniques to formulate more standardized mixed-integer programs [196]. As a result, we expect the formulation of optimization models to become easier in the upcoming years. This can increase the interest and accessibility of other communities in energy systems engineering tools as well.

\section{Closing the loop: Experimental expertise}

Finally, research expertise in computational modeling and experimentation are often concentrated in separate groups and housed in different locations. However, advancing energy systems to greater heights will depend on both quantitative and empirical knowledge and experience. It is usually the role of principal investigators of these groups to facilitate any teamwork between them. We have emphasized that increased interdisciplinary and industrial collaborations are necessary, and a significant reason for this is to close the loop between modeling and experimentation. Models can be unguided efforts toward abstract understanding if not supplemented by 
real-life results, and experiments can be tedious trial \& error excursions toward physical understanding if not supported by quantitative tools. While collaborations can help close the loop, they are difficult to secure due to lack of appropriate funding and limited by networks between researchers. Therefore, it is also imperative that modelers gain some empirical familiarity and experimentalists become more versed in computation. In this way, knowledge gaps between modeling and experimentation is minimized and progress in energy systems engineering is accelerated. We strongly believe that a holistic approach to energy systems engineering necessitates knocking down walls between modeling and experimentation.

\section{Conclusions}

In this commentary, we introduced the methodologies, applications, and a few possible future directions of energy systems engineering. We hope the methods and results show the importance and strength of an energy systems engineering approach to improve the efficiency of tomorrow's energy systems.

\section{Acknowledgments}

Not applicable.

\section{Funding}

The authors would like to acknowledge the financial support by the National Science Foundation (NSF Grant no. 1705423 and NSF Grant no. 1739977), RAPID Manufacturing Institute and RAPID SYNOPSIS Project (DE-EE0007888-09-03), CESMII Smart Manufacturing for Chemical Processing: Energy Efficient Operation for Air Separation Unit, and Shell Oil Company.

\section{Availability of data and materials}

Data sharing not applicable to this article as no datasets were generated or analyzed during the current study.

\section{Authors' contributions \\ Conceptualization, CDD, WWT, GSO, and ENP; writing-original draft preparation, CDD, WWT, and GSO; writing-review and editing, ENP; supervision, ENP. All authors read and approved the final manuscript.}

\section{Competing interests}

The authors declare that they have no competing interests.

\section{Publisher's Note}

Springer Nature remains neutral with regard to jurisdictional claims in published maps and institutional affiliations.

Received: 12 December 2018 Accepted: 27 February 2019 Published online: 10 April 2019

\section{References}

1. Shell Energy Transition Report. 2018. https://www.shell.com/energyand-innovation/the-energy-future/shell-energy-transition-report.html. Accessed 5 Feb 2019.

2. BP Energy Outlook 2018 Edition. https://www.bp.com/en/global/ corporate/energy-economics/energy-outlook.html. Accessed 5 Feb 2019.

3. International Energy Agency World Energy Outlook. 2017. https://www. iea.org/weo2017/. Accessed 5 Feb 2019.

4. IPCC Climate Change 2014: Synthesis Report. Contribution of Working Groups I, II and III to the Fifth Assessment Report of the Intergovernmental Panel on Climate Change. https://www.ipcc-nggip. iges.or.jp/public/2006gl/. Accessed 5 Feb 2019.
5. Liu P, Pistikopoulos EN, Li Z. Energy systems engineering: methodologies and applications. Front Energy Power Eng China. 2010;4(2):131-42.

6. Sheu EJ, Mitsos A, Eter AA, Mokheimer EM, Habib MA, Al-Qutub A. A review of hybrid solar-fossil fuel power generation systems and performance metrics. J Solar Energy Eng. 2012;134(4):041006.

7. Mitsos A, Asprion N, Floudas CA, Bortz M, Baldea M, Bonvin D, Caspar A, Schaefer P. Challenges in process optimization for new feedstocks and energy sources. Comput Chem Eng. 2018;113:209-21.

8. ExxonMobil 2018 Outlook for Energy: A View to 2040. https://corporate. exxonmobil.com/en/energy/energy-outlook/a-view-to-2040. Accessed 5 Feb 2019.

9. Liu P, Georgiadis MC, Pistikopoulos EN. Advances in energy systems engineering. Ind Eng Chem Res. 2011;50:4915-25.

10. Floudas CA, Niziolek AM, Onel O, Matthews LR. Multi-scale systems engineering for energy and the environment: Challenges and opportunities. AlChE J. 2016;62(3):602-23.

11. Grossmann IE. Mixed-integer programming approach for the synthesis of integrated process flowsheets. Comput Chem Eng. 1985;9(5):463-82.

12. Martin M, Adams TA. Future directions in process and product synthesis and design. In: Eden MR, lerapetritou MG, Towler GP, editors. 13th International Symposium on Process Systems Engineering (PSE 2018). Computer Aided Chemical Engineering, vol. 44. San Diego: Elsevier; 2018 p. 1-10. https://doi.org/10.1016/B978-0-444-64241-7.50001-X. http:// www.sciencedirect.com/science/article/pii/B978044464241750001X.

13. Floudas CA. Nonlinear and Mixed-Integer Optimization. New York: Oxford University Press: 1995.

14. Biegler LT, Grossmann IE, Westerberg AW. Systematic Methods for Chemical Process Design. Old Tappan: Prentice Hall; 1997.

15. Georgiadis MC, Kikkinides ES, Pistikopoulos EN. Energy Systems Engineering, vol. 5. Weinheim: Wiley; 2008.

16. Biegler $L T$, Lang $Y-d$, Lin W. Multi-scale optimization for process systems engineering. Comput Chem Eng. 2014;60:17-30.

17. Baliban RC, Elia JA, Floudas CA. Toward novel biomass, coal, and natural gas processes for satisfying current transportation fuel demands, 1 : Process alternatives, gasification modeling, process simulation, and economic analysis. Ind Eng Chem Res. 2010;49(16):7343-70.

18. Elia JA, Baliban RC, Floudas CA. Toward novel biomass, coal, and natura gas processes for satisfying current transportation fuel demands, 2: Simultaneous heat and power integration. Ind Eng Chem Res. 2010;49(16):7371-88.

19. Elia JA, Baliban RC, Floudas CA. Nationwide, regional, and statewide energy supply chain optimization for natural gas to liquid transportation fuel (gtl) systems. Ind Eng Chem Res. 2013;53(13):5366-97.

20. Elia JA, Baliban RC, Floudas CA. Nationwide energy supply chain analysis for hybrid feedstock processes with significant $\mathrm{co} 2$ emissions reduction. AlChE J. 2012;58(7):2142-54

21. Onel O, Niziolek AM, Floudas CA. Integrated biomass and fossil fuel systems towards the production of fuels and chemicals: state of the art approaches and future challenges. Curr Opin Chem Eng. 2015;9:66-74.

22. Onel O, Niziolek AM, Hasan MMF, Floudas CA. Municipal solid waste to liquid transportation fuels - Part I: Mathematical modeling of a municipal solid waste gasifier. Comput Chem Eng. 2014;71(0):636-47.

23. Georgiadis MC, Pistikopoulos EN. Integrated optimization of oil and gas production. In: Georgiadis MC, Kikkinides ES, Pistikopoulos EN, editors. Process Systems Engineering Volume 5: Energy Systems Engineering. Weinheim: Wiley-VCH Verlag GmBH \& Co. KGaA; 2008.

24. Cafaro DC, Grossmann IE. Strategic planning, design, and development of the shale gas supply chain network. AIChE J. 2014;60(6):2122-42.

25. Drouven MG, Grossmann IE, Cafaro DC. Stochastic programming models for optimal shale well development and refracturing planning under uncertainty. AIChE J. 2017;63(11):4799-813.

26. Siddhamshetty P, Wu K, Kwon JS-I. Optimization of simultaneously propagating multiple fractures in hydraulic fracturing to achieve uniform growth using data-based model reduction. Chem Eng Res Des. 2018;136:675-86.

27. Martín M, Grossmann IE. On the systematic synthesis of sustainable biorefineries. Ind Eng Chem Res. 2013;52(9):3044-64.

28. Kelloway A, Daoutidis P. Process synthesis of biorefineries: Optimization of biomass conversion to fuels and chemicals. Ind Eng Chem Res. 2014;53(13):5261-73.

29. Matthews LR, Niziolek AM, Onel O, Pinnaduwage N, Floudas CA. Biomass to liquid transportation fuels via biological and thermochemical 
conversion: Process synthesis and global optimization strategies. Ind Eng Chem Res. 2016;55(12):3203-25.

30. Liu P, Pistikopoulos EN, Li Z. An energy systems engineering approach to the optimal design of energy systems in commercial buildings. Energy Pol. 2010;38(8):4224-31.

31. Maréchal F, Weber C, Favrat D. Multiobjective design and optimization of urban energy systems. In: SE, Pistikopoulos EN, Georgiadis MC, Dua V, editors. Process Systems Engineering. Weinheim: Wiley; 2014. p. 39-83.

32. Cheng R, Xu Z, Liu P, Wang Z, Li Z, Jones I. A multi-region optimization planning model for china's power sector. Appl Energy. 2015;137:413-26.

33. Acha S, Mariaud A, Shah N, Markides CN. Optimal design and operation of distributed low-carbon energy technologies in commercial buildings. Energy. 2018;142:578-91

34. Subramanian A, Gundersen T, Adams T. Modeling and simulation of energy systems: A review. Processes. 2018;6(12):238.

35. Vlachos DG. A review of multiscale analysis: examples from systems biology, materials engineering, and other fluid-surface interacting systems. Adv Chem Eng. 2005;30:1-61.

36. Salciccioli M, Stamatakis M, Caratzoulas S, Vlachos DG. A review of multiscale modeling of metal-catalyzed reactions: Mechanism development for complexity and emergent behavior. Chem Eng Sci. 2011;66(19):4319-55.

37. Qin SJ. Survey on data-driven industrial process monitoring and diagnosis. Ann Rev Control. 2012;36(2):220-34.

38. Bhosekar A, lerapetritou M. Advances in surrogate based modeling, feasibility analysis, and optimization: A review. Comput Chem Eng. 2018;108:250-67.

39. Lee JH, Shin J, Realff MJ. Machine learning: Overview of the recent progresses and implications for the process systems engineering field. Comput Chem Eng. 2018;114:111-21.

40. Psichogios DC, Ungar LH. A hybrid neural network-first principles approach to process modeling. AIChE J. 1992;38(10):1499-511.

41. Thompson ML, Kramer MA. Modeling chemical processes using prior knowledge and neural networks. AIChE J. 1994;40(8):1328-40.

42. Bhutani N, Rangaiah G, Ray A. First-principles, data-based, and hybrid modeling and optimization of an industrial hydrocracking unit. Ind Eng Chem Res. 2006;45(23):7807-16.

43. Gong J, You F. Sustainable design and synthesis of energy systems. Curr Opin Chem Eng. 2015;10:77-86.

44. Andiappan V. State-of-the-art review of mathematical optimisation approaches for synthesis of energy systems. Process Integr Optim Sustain. 2017;1(3):165-88.

45. Heuberger CF, Staffell I, Shah N, Mac Dowell N. A systems approach to quantifying the value of power generation and energy storage technologies in future electricity networks. Comput Chem Eng. 2017;107:247-56.

46. Li J, Xiao X, Boukouvala F, Floudas CA, Zhao B, Du G, Su X, Liu H. Datadriven mathematical modeling and global optimization framework for entire petrochemical planning operations. AIChE J. 2016;62(9):3020-40.

47. Klatt K-U, Marquardt W. Perspectives for process systems engineering - personal views from academia and industry. Comput Chem Eng. 2009;33(3):536-50.

48. Grossmann IE, Caballero JA, Yeomans H. Mathematical programming approaches to the synthesis of chemical process systems. Korean J Chem Eng. 1999;16(4):407-26.

49. Nishida N, Stephanopoulos G, Westerberg AW. A review of process synthesis. AIChE J. 1981;27(3):321-51.

50. Yuan Z, Chen B. Process synthesis for addressing the sustainable energy systems and environmental issues. AlChE J. 2012;58(11):3370-89.

51. Furman KC, Sahinidis NV. A critical review and annotated bibliography for heat exchanger network synthesis in the 20th century. Ind Eng Chem Res. 2002;41(10):2335-70.

52. Odele O, Macchietto S. Computer aided molecular design: a novel method for optimal solvent selection. Fluid Phase Equilib. 1993;82:47-54.

53. Churi N, Achenie LE. Novel mathematical programming model for computer aided molecular design. Ind Eng Chem Res. 1996;35(10):3788-94.

54. Maranas CD. Optimal computer-aided molecular design: A polymer design case study. Ind Eng Chem Res. 1996;35(10):3403-14.

55. Castro-Lacouture D, Sefair JA, Flórez L, Medaglia AL. Optimization model for the selection of materials using a leed-based green building rating system in colombia. Build Environ. 2009;44(6):1162-70.
56. First EL, Gounaris CE, Floudas CA. Predictive framework for shape-selective separations in three-dimensional zeolites and metal-organic frameworks. Langmuir. 2013;29(18):5599-608.

57. Hanselman CL, Gounaris CE. A mathematical optimization framework for the design of nanopatterned surfaces. AIChE J. 2016;62(9):3250-63.

58. Lutze P, Babi DK, Woodley JM, Gani R. Phenomena based methodology for process synthesis incorporating process intensification. Ind Eng Chem Res. 2013;52(22):7127-44.

59. Demirel SE, Li J, Hasan MF. Systematic process intensification using building blocks. Comput Chem Eng. 2017;105:2-38.

60. Tian Y, Demirel SE, Hasan MF, Pistikopoulos EN. An overview of process systems engineering approaches for process intensification: State of the art. Chem Eng Processing-Process Intensif. 2018;133:278-93.

61. Melo MT, Nickel S, Saldanha-Da-Gama F. Facility location and supply chain management-a review. Eur J Oper Res. 2009;196(2):401-12.

62. Papageorgiou LG. Supply chain optimisation for the process industries: Advances and opportunities. Comput Chem Eng. 2009;33(12):1931-8.

63. Hasan MF, Boukouvala F, First EL, Floudas CA. Nationwide, regional, and statewide $\mathrm{CO} 2$ capture, utilization, and sequestration supply chain network optimization. Ind Eng Chem Res. 2014;53(18):7489-506.

64. Kantorovich LV. Mathematical methods of organizing and planning production. Manag Sci. 1960;6(4):366-422.

65. Dantzig GB. Programming in a linear structure. Econometrica. 1949;17: 73-74.

66. Balas E. Disjunctive programming. Ann Discret Math. 1979;5:3-51.

67. Lodi A. Mixed integer programming computation. In: 50 Years of Integer Programming 1958-2008. New York: Springer; 2010. p. 619-45.

68. Bixby RE. A brief history of linear and mixed-integer programming computation. Documenta Mathematica, Extra Volume: Optimization Stories. 2012;107-21.

69. Baliban RC, Elia JA, Misener R, Floudas CA. Global optimization of a minlp process synthesis model for thermochemical based conversion of hybrid coal, biomass, and natural gas to liquid fuels. Comput Chem Eng. 2012;42:64-86

70. Floudas CA. Deterministic Global Optimization: Theory, Methods and Applications, vol. 37. Boston: Springer; 2000

71. Boukouvala F, Misener R, Floudas CA. Global optimization advances in mixed-integer nonlinear programming, minlp, and constrained derivative-free optimization, cdfo. Eur J Oper Res. 2016;252(3):701-27.

72. Åström KJ, Hägglund T. PID Controllers: Theory, Design, and Tuning, vol. 2. Research Triangle Park: Instrument Society of America; 1995.

73. Prett DM, Ramaker BL, Cutler CR. Dynamic matrix control method. 1982. USPatent 4,349,869.

74. Rawlings JB, Mayne DQ. Model Predictive Control: Theory and Design. Madison: Nob Hill Publishing, LLC; 2009

75. Bose S, Pekny J. A model predictive framework for planning and scheduling problems: a case study of consumer goods supply chain. Comput Chem Eng. 2000;24(2-7):329-35.

76. Perea-Lopez E, Ydstie BE, Grossmann IE. A model predictive control strategy for supply chain optimization. Comput Chem Eng. 2003;27(8-9): 1201-18.

77. Subramanian K, Maravelias CT, Rawlings JB. A state-space model for chemical production scheduling. Comput Chem Eng. 2012;47:97-110.

78. Dias LS, lerapetritou MG. From process control to supply chain management: An overview of integrated decision making strategies. Comput Chem Eng. 2017;106:826-35.

79. Daoutidis P, Lee JH, Harjunkoski I, Skogestad S, Baldea M, Georgakis C. Integrating operations and control: A perspective and roadmap for future research. Comput Chem Eng. 2018;115:179-84.

80. Bellman R. The theory of dynamic programming Technical report. 1954.

81. De Farias DP, Van Roy B. The linear programming approach to approximate dynamic programming. Oper Res. 2003;51(6):850-65.

82. Harjunkoski I, Maravelias CT, Bongers P, Castro PM, Engell S, Grossmann IE, Hooker J, Méndez C, Sand G, Wassick J. Scope for industrial applications of production scheduling models and solution methods. Comput Chem Eng. 2014;62:161-93.

83. Biegler LT. Solution of dynamic optimization problems by successive quadratic programming and orthogonal collocation. Comput Chem Eng. 1984;8(3-4):243-7.

84. Dadebo S, McAuley K. Dynamic optimization of constrained chemical engineering problems using dynamic programming. Comput Chem Eng. 1995;19(5):513-25. 
85. Dowling AW, Kumar R, Zavala VM. A multi-scale optimization framework for electricity market participation. Appl Energy. 2017;190:147-64.

86. Salas DF, Powell WB. Benchmarking a scalable approximate dynamic programming algorithm for stochastic control of grid-level energy storage. INFORMS J Comput. 2018;30(1):106-23.

87. Yuan Z, Chen B, Sin G, Gani R. State-of-the-art and progress in the optimization-based simultaneous design and control for chemical processes. AlChE J. 2012;58(6):1640-59.

88. Sharifzadeh M. Integration of process design and control: A review. Chem Eng Res Des. 2013;91(12):2515-49.

89. Pistikopoulos EN, Diangelakis NA, Oberdieck R, Papathanasiou MM, Nascu I, Sun M. Paroc_-an integrated framework and software platform for the optimisation and advanced model-based control of process systems. Chem Eng Sci. 2015;136:115-38.

90. Gal T, Greenberg H. Advances in Sensitivity Analysis and Parametric Programming International Series in Oper Res \& Management Science, Vol 6. Boston: Kluwer Academic Publishers; 1997.

91. Pistikopoulos EN, Diangelakis NA. Towards the integration of process design, control and scheduling: Are we getting closer?. Comput Chem Eng. 2016;91:85-92.

92. Diangelakis NA, Burnak B, Katz JP, Pistikopoulos EN. Process design and control optimization: A simultaneous approach by multi-parametric programming. AlChE J. 2017;63(11):4827-46.

93. Zhang Q, Martín M, Grossmann IE. Integrated design and operation of renewables-based fuels and power production networks. Comput Chem Eng. 2018.

94. Gabrielli P, Gazzani M, Martelli E, Mazzotti M. Optimal design of multi-energy systems with seasonal storage. Appl Energy. 2018;219:408-24.

95. Bahl B, Lützow J, Shu D, Hollermann DE, Lampe M, Hennen M, Bardow A. Rigorous synthesis of energy systems by decomposition via time-series aggregation. Comput Chem Eng. 2018;112:70-81.

96. Allman A, Palys MJ, Daoutidis P. Scheduling-informed optimal design of systems with time-varying operation: A wind-powered ammonia case study. AIChE J. 2018.

97. Bakshi BR, Fiksel J. The quest for sustainability: Challenges for process systems engineering. AIChE J. 2003;49(6):1350-8.

98. Liu P, Pistikopoulos EN, Li Z. A multi-objective optimization approach to polygeneration energy systems design. AIChE J. 2010;56(5):1218-34.

99. Fazlollahi S, Mandel P, Becker G, Maréchal F. Methods for multi-objective investment and operating optimization of complex energy systems. Energy. 2012;45(1):12-22.

100. Pohekar S, Ramachandran M. Application of multi-criteria decision making to sustainable energy planning - a review. Renew Sust Energy Rev. 2004;8(4):365-81.

101. Wang J-J, Jing Y-Y, Zhang C-F, Zhao J-H. Review on multi-criteria decision analysis aid in sustainable energy decision-making. Renew Sust Energy Rev. 2009;13(9):2263-78.

102. Rangaiah GP. Multi-objective Optimization: Techniques and Applications in Chemical Engineering, vol. 1. Hackensack: World Scientific; 2009.

103. Marler RT, Arora JS. Survey of multi-objective optimization methods for engineering. Struct Multidiscip Optim. 2004;26(6):369-95.

104. Haimes Y. On a bicriterion formulation of the problems of integrated system identification and system optimization. IEEE Trans Syst Man Cybern. 1971;1(3):296-7.

105. Pistikopoulos EN. Uncertainty in process design and operations. Comput Chem Eng. 1995;19:553-63.

106. Sahinidis NV. Optimization under uncertainty: state-of-the-art and opportunities. Comput Chem Eng. 2004;28(6-7):971-83.

107. Grossmann IE, Apap RM, Calfa BA, García-Herreros P, Zhang Q. Recent advances in mathematical programming techniques for the optimization of process systems under uncertainty. Comput Chem Eng. 2016;91:3-14.

108. Kall P, Wallace SW, Kall P. Stochastic Programming. New York: Springer; 1994.

109. Birge JR, Louveaux F. Introduction to Stochastic Programming. New York: Springer; 2011.

110. Kleywegt AJ, Shapiro A, Homem-de-Mello T. The sample average approximation method for stochastic discrete optimization. SIAM J Optim. 2002;12(2):479-502.

111. Van Slyke RM, Wets R. L-shaped linear programs with applications to optimal control and stochastic programming. SIAM J Appl Math. 1969;17(4):638-63.
112. Soyster AL. Convex programming with set-inclusive constraints and applications to inexact linear programming. Oper Res. 1973;21(5):1154-7.

113. Ben-Tal A, Nemirovski A. Robust convex optimization. Math Oper Res. 1998;23(4):769-805

114. Ben-Tal A, Nemirovski A. Robust solutions of uncertain linear programs. Oper Res Lett. 1999;25(1):1-13.

115. Bertsimas D, Sim M. The price of robustness. Oper Res. 2004;52(1):35-53.

116. Li Z, Tang Q, Floudas CA. A comparative theoretical and computational study on robust counterpart optimization: li probabilistic guarantees on constraint satisfaction. Ind Eng Chem Res. 2012;51(19):6769-88.

117. Guzman YA, Matthews LR, Floudas CA. New a priori and a posteriori probabilistic bounds for robust counterpart optimization: I unknown probability distributions. Comput Chem Eng. 2016;84:568-98.

118. Guzman YA, Matthews LR, Floudas CA. New a priori and a posteriori probabilistic bounds for robust counterpart optimization: li a priori bounds for known symmetric and asymmetric probability distributions. Comput Chem Eng. 2017;101:279-311.

119. Guzman YA, Matthews LR, Floudas CA. New a priori and a posterior probabilistic bounds for robust counterpart optimization: lii exact and near-exact a posteriori expressions for known probability distributions. Comput Chem Eng. 2017;103:116-43.

120. Matthews LR, Guzman YA, Floudas CA. Generalized robust counterparts for constraints with bounded and unbounded uncertain parameters. Comput Chem Eng. 2018;116:451-67.

121. Tarhan B, Grossmann IE, Goel V. Stochastic programming approach for the planning of offshore oil or gas field infrastructure under decision-dependent uncertainty. Ind Eng Chem Res. 2009;48(6):3078-97.

122. Zhang Q, Grossmann IE, Heuberger CF, Sundaramoorthy A, Pinto JM. Ai separation with cryogenic energy storage: optimal scheduling considering electric energy and reserve markets. AIChE J. 2015;61(5):1547-58.

123. Amaran S, Zhang T, Sahinidis NV, Sharda B, Bury SJ. Medium-term maintenance turnaround planning under uncertainty for integrated chemical sites. Comput Chem Eng. 2016;84:422-33.

124. Tso WW, Niziolek AM, Onel O, Demirhan CD, Floudas CA, Pistikopoulos EN. Enhancing natural gas-to-liquids (gtl) processes through chemical looping for syngas production: Process synthesis and global optimization. Comput Chem Eng. 2018;45(23):7807-16.

125. Beykal B, Boukouvala F, Floudas CA, Pistikopoulos EN. Optimal design of energy systems using constrained grey-box multi-objective optimization. Comput Chem Eng. 2018;116:488-502.

126. Tso WW, Demirhan CD, Powell JB, Pistikopoulos EN. Toward Optimal Synthesis of Renewable Ammonia and Methanol Processes (RAMP). In Eden MR, lerapetritou MG, Towler GP, editors. 13th International Symposium on Process Systems Engineering (PSE 2018). Computer Aided Chemical Engineering, vol. 44. San Diego: Elsevier; 2018. p. 17051710. https://doi.org/10.1016/B978-0-444-64241-7.50279-2. http:// www.sciencedirect.com/science/article/pii/B9780444642417502792.

127. Demirhan CD, Tso WW, Powell JB, Pistikopoulos EN. Sustainable ammonia production through process synthesis and global optimization. AICHE J. 2018. In press. https://doi.org/10.1002/aic.16498.

128. Niziolek AM, Onur O, Tian Y, Floudas CA, Pistikopoulos EN. Municipal solid waste to liquid transportation fuels - part iii: An optimization-based nationwide supply chain management framework. Comput Chem Eng. 2018;116:468-87.

129. Ogumerem GS, Kim C, Kesisoglou I, Diangelakis NA, Pistikopoulos EN. A multi-objective optimization for the design and operation of a hydrogen network for transportation fuel. Chem Eng Res Des. 2018;131:279-92.

130. Liu P, Gerogiorgis DI, Pistikopoulos EN. Modeling and optimization of polygeneration energy systems. Catal Today. 2007;127(1-4):347-59.

131. Liu P, Pistikopoulos EN, Li Z. A mixed-integer optimization approach for polygeneration energy systems design. Comput Chem Eng. 2009;33(3): 759-68.

132. Liu P, Pistikopoulos EN, Li Z. Decomposition based stochastic programming approach for polygeneration energy systems design under uncertainty. Ind Eng Chem Res. 2010;49(7):3295-305.

133. Diangelakis NA, Manthanwar AM, Pistikopoulos EN. A framework for design and control optimisation. application on a chp system. In: Proceedings of the 8th International Conference on Foundations of Computer-Aided Process Design. Computer Aided Chemical Engineering, vol. 34. Cle Elum, Washington: Elsevier; 2014. p. 765-770.

134. Diangelakis NA, Pistikopoulos EN. Modelling, design and control optimization of a residential scale chp system. In: Kopanos GM, Liu P, 
Georgiadis MC, editors. Advances in Energy Systems Engineering. Weinheim: Springer; 2017.

135. Panos C, Kouramas KI, Georgiadis MC, Pistikopoulos EN. Modelling and explicit model predictive control for pem fuel cell systems. Chem Eng Sci. 2012;67(1):15-25.

136. Zhao Y, Pistikopoulos EN. Dynamic modelling and parametric control for the polymer electrolyte membrane fuel cell system. J of Power Sources. 2013;232:270-8.

137. Ziogou C, Pistikopoulos EN, Georgiadis MC, Voutetakis S, Papadopoulou S. Empowering the performance of advanced nmpc by multiparametric programming - an application to a pem fuel cell system. Ind Eng Chem Res. 2013;52(13):4863-73.

138. Ogumerem GS, Pistikopoulos EN. Dynamic modeling, optimization and explicit control of a pem water electrolysis process. Smart Sust Manuf Syst. 2018:2:25-43.

139. Avraamidou S, Milhorn A, Sarwar O, Pistikopoulos EN. Towards a quantitative food-energy-water nexus metric to facilitate decision making in process systems: A case study on a dairy production plant. In: 28th European Symposium on Computer-Aided Process Engineering (ESCAPE-28), vol. 43. Graz, Austria: Elsevier; 2018. p. 391-6.

140. Avraamidou S, Beykal B, Pistikopoulos I, Pistikopoulos EN. A hierarchical food-energy-water nexus (few-n) decision-making approach for land use optimization. In: 13th International Symposium on Process Systems Engineering (PSE 2018). San Diego: Elsevier; 2018. p. 1885-90.

141. Nie Y, Avraamidou S, Li J, Xiao X, Pistikopoulos EN. Land use modeling and optimization based on food-energy-water nexus: a case study on crop-livestock systems. In: 13th International Symposium on Process Systems Engineering (PSE 2018), vol. 44. San Diego: Elsevier; 2018. p. 1939-44.

142. Onel M, Kieslich CA, Guzman YA, Floudas CA, Pistikopoulos EN. Big data approach to batch process monitoring: Simultaneous fault detection and identification using nonlinear support vector machine-based feature selection. Comput Chem Eng. 2018;115:46-63.

143. Onel M, Kieslich CA, Pistikopoulos EN. A nonlinear support vector machine-based feature selection approach for fault detection and diagnosis: Application to the Tennessee Eastman process. AICHE J. 2019;65(3):992-1005. In press. https://doi.org/10.1002/aic.16497.

144. United States Geological Survey: Nitrogen - Statistics and Information. https://minerals.usgs.gov/minerals/pubs/commodity/nitrogen/. Accessed 5 Feb 2019

145. Department of Energy Potential Roles of Ammonia in a Hydrogen Economy: A Study of Issues Related to the Use of Ammonia for On-Board Vehicular Hydrogen Storage. https://www.energy.gov/eere/ fuelcells/downloads/potential-roles-ammonia-hydrogen-economy. Accessed 5 Feb 2019

146. Appl M. Ammonia: Principles and Industrial Practice. Weinheim: Wiley-VCH Verlag; 1999.

147. Ammonia Production Causes $1 \%$ of Total Global GHG Emissions. https://ammoniaindustry.com/ammonia-production-causes-1-percentof-total-global-ghg-emissions/. Accessed 5 Feb 2019.

148. Baliban RC, Elia JA, Floudas CA. Optimization framework for the simultaneous process synthesis, heat and power integration of a thermochemical hybrid biomass, coal, and natural gas facility. Comput Chem Eng. 2011;35(9):1647-90.

149. Baliban RC, Elia JA, Floudas CA. Simultaneous process synthesis, heat, power, and water integration of thermochemical hybrid biomass, coal, and natural gas facilities. Comput Chem Eng. 2012;37(10):297-327.

150. DOE Energy Storage. https://www.energy.gov/oe/activities/technologydevelopment/energy-storage. Accessed 5 Feb 2019

151. IRENA Energy Storage. http://www.irena.org/costs/Power-GenerationCosts/Energy-Storage. Accessed 5 Feb 2019.

152. IEA Technology Roadmap: Energy Storage. https://www.iea.org/publications/ freepublications/publication/TechnologyRoadmapEnergystorage.pdf.

153. Chen H, Cong TN, Yang W, Tan C, Li Y, Ding Y. Progress in electrical energy storage system: A critical review. Prog Nat Sci. 2009;19(3):291-312.

154. Luo X, Wang J, Dooner M, Clarke J. Overview of current development in electrical energy storage technologies and the application potential in power system operation. Appl Energy. 2015;137:511-36.

155. Zakeri B, Syri S. Electrical energy storage systems: A comparative life cycle cost analysis. Renew Sust Energy Rev. 2015;42:569-96.

156. Mazloomi K, Gomes C. Hydrogen as an energy carrier: prospects and challenges. Renew Sust Energy Rev. 2012;16(5):3024-33.
157. Klerke A, Christensen CH, Nørskov JK, Vegge T. Ammonia for hydrogen storage: challenges and opportunities. J Mater Chem. 2008;18(20):2304-10

158. Wang G, Mitsos A, Marquardt W. Conceptual design of ammonia-based energy storage system: System design and time-invariant performance. AlChE J. 2017;63(5):1620-37.

159. Olah GA. Beyond oil and gas: the methanol economy. Angew Chem Int Ed. 2005;44(18):2636-9.

160. Almansoori A, Shah N. Design and operation of a future hydrogen supply chain: multi-period model. Int J Hydrog Energy. 2009;34(19):7883-97.

161. Allman A, Daoutidis P, Tiffany D, Kelley S. A framework for ammonia supply chain optimization incorporating conventional and renewable generation. AlChE J. 2017;63(10):4390-402.

162. Palys MJ, Allman A, Daoutidis P. Exploring the benefits of modular renewable-powered ammonia production: A supply chain optimization study. Ind Eng Chem Res. 2018

163. Tso WW, Demirhan CD, Lee SY, Song H, Powell JB, Pistikopoulos EN. Energy Carrier Supply Chain Optimization: A Texas Case Study. in press.

164. Ursua A, Gandia LM, Sanchis P. Hydrogen production from water electrolysis: current status and future trends. Proc IEEE. 2012;100(2): 410-26.

165. Carmo M, Fritz DL, Mergel J, Stolten D. A comprehensive review on pem water electrolysis. Int J Hydrogen Energy. 2013;38(12):4901-34.

166. Ni M, Leung MK, Leung DY. Technological development of hydrogen production by solid oxide electrolyzer cell (soec). Int J Hydrogen Energy. 2008;33(9):2337-54.

167. Zeng K, Zhang D. Recent progress in alkaline water electrolysis for hydrogen production and applications. Prog Energy Combust Sci. 2010;36(3):307-26

168. Eigeldinger J, Vogt $\mathrm{H}$. The bubble coverage of gas-evolving electrodes in a flowing electrolyte. Electrochim Acta. 2000;45(27):4449-56.

169. Marangio F, Santarelli M, Cali M. Theoretical model and experimental analysis of a high pressure pem water electrolyser for hydrogen production. Int J Hydrogen Energy. 2009;34(3):1143-58.

170. Awasthi A, Scott K, Basu S. Dynamic modeling and simulation of a proton exchange membrane electrolyzer for hydrogen production. Int J Hydrogen Energy. 2011;36(22):14779-86.

171. García-Valverde R, Espinosa N, Urbina A. Simple pem water electrolyser model and experimental validation. Int J Hydrogen Energy. 2012;37(2): 1927-38.

172. Bemporad A, Morari M, Dua V, Pistikopoulos EN. The explicit linear quadratic regulator for constrained systems. Automatica. 2002;38(1):3-20.

173. Chiang L, Lu B, Castillo I. Big data analytics in chemical engineering. Annu Rev Chem Biomol Eng. 2017;8:63-85.

174. Edgar TF, Pistikopoulos EN. Smart manufacturing and energy systems. Comput Chem Eng. 2018;114:130-44.

175. Siirola JJ, Rudd DF. Computer-aided synthesis of chemical process designs from reaction path data to the process task network. Ind Eng Chem Fundam. 1971;10(3):353-62.

176. Stephanopoulos $G$. Research program on artificial intelligence in process engineering. Chem Eng Educ. 1986;20(4):182-185192.

177. Venkatasubramanian $V$. Artificial intelligence in process engineering Chem Eng Educ. 1986;20(4):188-93.

178. Bostrum N. Superintelligence: Paths, Dangers, Strategies. Oxford: Oxford University Press; 2014.

179. Ibm watson: How cognitive computing can be applied to big data challenges in life sciences research. Clin Ther. 2016;38(4):688-701.

180. Silver D, Huang A, Maddison CJ, Guez A, Sifre L, Van Den Driessche G, Schrittwieser J, Antonoglou I, Panneershelvam V, Lanctot M, Dieleman S, Grewe D, Nham J, Kalchbrenner N, Sutskever I, Lillicrap T, Leach M, Kavukcuoglu K, Graepel T, Hassabis D. Mastering the game of go with deep neural networks and tree search. Nature. 2016;529(7587):484-9.

181. Venkatasubramanian $\mathrm{V}$. The promise of artificial intelligence in chemical engineering: Is it here, finally?. AIChE J. 2019;65(2):466-78. https://doi. org/10.1002/aic.16489. cited By 0 .

182. Goldsmith BR, Esterhuizen J, Liu J-X, Bartel CJ, Sutton C. Machine learning for heterogeneous catalyst design and discovery. AlChE J. 2018;64(7):2311-23.

183. Medford AJ, Kunz MR, Ewing SM, Borders T, Fushimi R. Extracting knowledge from data through catalysis informatics. ACS Catalysis. 2018;8(8):7403-29.

184. Suresh P, Hsu S-H, Akkisetty P, Reklaitis GV, Venkatasubramanian V. Ontomodel: Ontological mathematical modeling knowledge 
management in pharmaceutical product development, 1: Conceptual framework. Ind Eng Chem Res. 2010;49(17):7758-67.

185. Toward creating an environment of cooperation between water, energy, and food stakeholders in san antonio. Sci Total Environ. 2019;651:2913-26.

186. Garcia DJ, You F. The water-energy-food nexus and process systems engineering: A new focus. Comput Chem Eng. 2016;91:49-67. 12th International Symposium on Process Systems Engineering \& 25th European Symposium of Computer Aided Process Engineering (PSE-2015/ESCAPE-25), 31 May - 4 June 2015, Copenhagen, Denmark.

187. Tsay C, Pattison RC, Piana MR, Baldea M. A survey of optimal process design capabilities and practices in the chemical and petrochemical industries. Comput Chem Eng. 2018;112:180-9.

188. The Rapid Advancement in Process Intensification Deployment (RAPID) Institute. https://www.aiche.org/rapid. Accessed 5 Feb 2019.

189. Clean Energy Smart Manufacturing Innovation Institute (CESMII). https:// www.cesmii.org/.

190. Brook A, Kendrick D, Meeraus A. Gams, a user's guide. SIGNUM NewsI. 1988;23(3-4):10-11.

191. Fourer R, Gay DM, Kernighan B. AMPL: A Modeling Language for Mathematical Programming. Pacific Grove: Thomson/Cengage Learn; 2003.

192. Hart WE, Laird C, Watson JP, Woodruff DL. Pyomo - Optimization Modeling in Python. New York: Springer; 2012.

193. Lubin M, Dunning I. Computing in operations research using julia. INFORMS J Comput. 2015;27(2):238-48.

194. Turkay M, Grossmann IE. Logic-based minlp algorithms for the optimal synthesis of process networks. Comput Chem Eng. 1996;20(8):959-78.

195. Grossmann IE, Ruiz JP. Generalized disjunctive programming: A framework for formulation and alternative algorithms for minlp optimization. In: Mixed Integer Nonlinear Programming. New York: Springer; 2012. p. 93-115.

196. Chen Q, Grossmann IE. Recent developments and challenges in optimization-based process synthesis. Annu Rev Chem Biomol Eng. 2017:8(1):249-83.

Ready to submit your research? Choose BMC and benefit from:

- fast, convenient online submission

- thorough peer review by experienced researchers in your field

- rapid publication on acceptance

- support for research data, including large and complex data types

- gold Open Access which fosters wider collaboration and increased citations

- maximum visibility for your research: over $100 \mathrm{M}$ website views per year

At BMC, research is always in progress.

Learn more biomedcentral.com/submissions 